\title{
Modelos experimentales de traumatismo craneoencefálico
}

\author{
R. Prieto; R. Gutiérrez-González; J.M. Pascual*; J.M. Roda**; S. Cerdán***; J. Matias-Guiu**** y J.A. Barcia
}

Servicios de Neurocirugía, Hospital Universitario Clínico San Carlos; *Hospital Universitario de La Princesa; **Hospital Universitario de La Paz; ***Laboratorio de Resonancia Magnética, Instituto de Investigaciones Biomédicas Alberto Sols; ****Servicio de Neurología, Hospital Universitario Clínico San Carlos; Madrid, España.

Resumen

Objetivo. El objetivo de este trabajo es proporcionar una revisión de los diversos modelos experimentales de traumatismo craneoencefálico (TCE) que se han desarrollado para la investigación del daño cerebral traumático tanto en condiciones in vivo como in vitro, así como detallar los principales conocimientos fisiopatológicos obtenidos a partir de su aplicación. Se expone de forma sintética tanto el tipo de lesión cerebral traumática que cada modelo reproduce como los detalles técnicos necesarios para su utilización por investigadores en el campo del trauma cerebral.

Desarrollo. El pronóstico de los pacientes que han sufrido un TCE ha mejorado gracias a las medidas iniciales de estabilización hemodinámica y control de la vía aérea, pero no existe todavía ningún tratamiento específico y eficaz para detener o limitar las lesiones cerebrales causadas por el traumatismo, exceptuando las medidas de control de la presión arterial y la presión intracraneal. Entender la fisiopatología del TCE es el paso básico y fundamental para desarrollar posibles abordajes terapéuticos con aplicación clínica. El daño cerebral traumático en humanos es una patología heterogénea y muy compleja. Por ello, cada modelo experimental se ha desarrollado con el objetivo de reproducir un tipo concreto de las diferentes lesiones cerebrales observadas en pacientes tras un TCE. El uso de estos modelos ha permitido ampliar el conocimiento sobre la fisiopatología del daño cerebral traumático, incluyendo las alteraciones inducidas a nivel celular y molecular.

Conclusión. Los modelos experimentales suponen actualmente la mejor herramienta para el estudio de los mecanismos subyacentes a las lesiones cerebrales traumáticas, pero su simplicidad y por lo tanto su incapacidad de reproducir exactamente el daño heterogéneo observado en la práctica clínica puede ser uno de los motivos que explique la discrepancia en la respuesta

Recibido: 24-04-08. aceptado: 25-11-08 terapéutica entre los estudios experimentales y clínicos.

PALABRAS CLAVE: TCE. Daño cerebral traumático. Edema cerebral. Contusión cerebral. Modelos experimentales.

Experimental models of traumatic brain injury

Summary

Aim. To provide a summary of the different experimental models of traumatic brain injury (TBI) designed under both in vivo and in vitro conditions. A comprehensible review of the specific types of brain lesions induced, as well as the technical details to reproduce each model at the laboratory is given.

Development. Outcome of patients suffering from a TBI has significantly improved with the rapid application of vital supporting measures in addition to a strict control of blood and intracranial pressure at the intensive care units. However no specific treatment for post-traumatic brain lesions has proven as efficacious in the clinical settings. A deeper knowlegde of the physiopathological events associated with TBI is necessary for the development of new specific therapies. Due to the heterogeneity of the human TBI, each experimental model has been designed to reproduce a different type of brain lesion. Experimental TBI models allow the study of the dynamic evolution of brain injuries under controlled conditions. Usefulness of experimental

Abreviaturas. BHE: barrera hemato-encefálica. CCI: controlled cortical impact (impacto cortical controlado). CDA: coeficiente de difusión aparente. GSH/GSSG: cociente entre glutation reducido y oxidado. HPLC: high performance liquid chromatography (cromatografía líquida de alta eficiencia). KPa: kilopascales. LAD: lesión axonal difusa. LFP: lateral fluid percussion (percusión lateral por fluido). NAD: encima nicotínica. RM: resonancia magética. TC: tomografia computarizada. TCE: traumatismo craneo-encefálico. 
models is limited by their reliability and reproducibility among different researchers. Small rodents have been the preferred animals to reproduce TBI injuries, mainly due to the similar cerebral physiology shared by these animals and the human beings.

Conclusion. The use of experimental models of TBI is the most appropiate tool to study the mechanisms underlying this type of injury. However their simplicity precludes an exact reproduction of the heterogeneous cerebral damage observed in clinical settings. This could be the main reason for the discrepancies observed in the therapeutic effects of treatments between experimental and clinical studies.

KEY WORKS: TBI. Traumatic brain injury. Brain edema. Cerebral contusion. Experimental models.

\section{Introducción}

El traumatismo craneoencefálico (TCE) es uno de los problemas de salud pública más relevantes, que afecta anualmente a más del $2 \%$ de la población de Estados Unidos y representa una de las causas más importantes de morbi-mortalidad, especialmente en la población joven ${ }^{15}$. En Europa la incidencia es considerablemente mayor, existiendo 235/10.0000 habitantes al año que requieren hospitalización y/o fallecen tras sufrir un TCE ${ }^{109}$. Se calcula que aproximadamente un $90 \%$ de las personas que sufren un TCE van a requerir atención médica hospitalaria. Respecto a la incidencia concreta en España, desafortunadamente no disponemos de fuentes fiables, pero puede estimarse que el número de pacientes hospitalizados anualmente por daño cerebral traumático supera a la suma de los pacientes diagnosticados de esclerosis múltiple, cáncer de mama y daño medular traumático ${ }^{64}$. El TCE es así mismo la principal causa de muerte en la población menor de 45 años ${ }^{14,115}$, siendo exclusivamente superado por las enfermedades cardiovasculares y el cáncer en el grupo de pacientes mayores de 65 años. La incidencia es mayor entre los hombres, con una relación hombre/mujer de 3/1 y afecta sobre todo a pacientes entre 15 y 25 años.

Las lesiones cerebrales causadas por un traumatismo craneal se deben básicamente a la intensidad y rapidez con que la energía liberada por el traumatismo actúa sobre el cráneo. El pronóstico de un paciente que ha sufrido un TCE va a depender por ello, tanto de la cantidad de energía liberada en el traumatismo como del mecanismo causal del mismo. En los países desarrollados la causa más frecuente de TCE son los accidentes de tráfico ${ }^{109}$. Una evolución desfavorable, ya sea la muerte, el estado vegetativo permanente o una morbilidad grave postraumática, puede presentarse hasta en un $20 \%$ de los $\operatorname{casos}^{14,37}$. A pesar de la intensa investigación realizada en las últimas décadas no existe actualmente ningún tratamiento específico y efectivo del daño cerebral traumático, exceptuando la evacuación quirúrgica de hematomas intracraneales con efecto de masa y un control estricto de la presión arterial y la presión intracraneal del paciente. Un conocimiento más exhaustivo de las diversas alteraciones fisiopatológicas producidas en el daño cerebral traumático, especialmente a nivel celular y molecular, es un requerimiento básico previo a la búsqueda de cualquier terapia capaz de interferir específicamente con los mecanismos subyacentes a las lesiones cerebrales traumáticas. Los modelos experimentales suponen en este momento la mejor herramienta de que disponemos para estudiar las múltiples alteraciones fisiopatológicas asociadas al daño cerebral traumático así como para la investigación de nuevas estrategias terapéuticas ${ }^{82}$.

Las lesiones cerebrales traumáticas presentes en cada paciente son únicas y sus factores desencadenantes sumamente complejos, existiendo por ello tanto una gran variedad de lesiones como una infinidad de combinaciones de las mismas según el grado de gravedad lesional y la localización específica de cada una de ellas. Clínicamente se pueden diferenciar dos grandes grupos de lesiones del parénquima cerebral secundarias a un TCE: lesiones traumáticas focales y lesiones difusas ${ }^{40}$. Las lesiones focales incluyen las contusiones cerebrales y los hematomas intracraneales, estos últimos de localización epidural, subdural o intraparenquimatosa. Las lesiones focales son fácilmente identificables en los estudios de tomografía computarizada (TC). Respecto a las lesiones difusas, su presencia puede inferirse o sospecharse ante la ausencia de hallazgos patológicos en las imágenes de $\mathrm{TC}$ en pacientes con deterioro neurológico inicial o progresivo. Las lesiones difusas incluyen la lesión axonal difusa (LAD) y el edema cerebral difuso (swelling cerebral) ${ }^{91}$. La complejidad y heterogeneidad del TCE en humanos ha conducido al diseño de una gran variedad de modelos experimentales animales, cada uno de los cuáles reproduce un aspecto concreto del daño observado en la clínica ${ }^{67}$. Algunos modelos reproducen fundamentalmente lesiones cerebrales focales ${ }^{29,31,79}$, mientras que otros reproducen un daño cerebral difuso ${ }^{20,74}$. En la última década, junto a los modelos animales de TCE se han desarrollado una serie de modelos experimentales in vitro que permiten estudiar de forma más precisa condiciones específicas del daño cerebral traumático a nivel celular. Los modelos experimentales nos permiten analizar múltiples parámetros tanto fisiológicos, neuroquímicos, patológicos o de conducta cuyas modificaciones se hallan asociadas al desarrollo y progresión de cada tipo de lesión cerebral post-traumática. Además, permiten evaluar la utilidad de nuevas herramientas diagnósticas y ensayar los efectos de potenciales agentes terapéuticos.

El objetivo de esta revisión es tratar de que el lector se familiarice con los diferentes modelos experimentales 
de trauma cerebral desarrollados hasta el momento actual, tanto en condiciones in vivo como in vitro, así como delimitar sus principales ventajas e inconvenientes. Comenzaremos presentando los mecanismos físicos causales del daño cerebral traumático y los tipos de lesiones cerebrales traumáticas que se observan en la práctica clínica. A continuación expondremos brevemente las características técnicas de cada modelo experimental, haciendo énfasis en el tipo de lesión cerebral que cada uno de ellos reproduce, sus ventajas e inconvenientes y los principales conocimientos científicos que han proporcionado. Por último proporcionaremos detalles técnicos de aquellos modelos más utilizados en la investigación actual que puedan ser de interés para los clínicos involucrados en la investigación básica del daño cerebral traumático.

\section{Mecanismos físicos del daño cerebral traumático}

Las fuerzas mecánicas responsables del daño cerebral traumático determinan una respuesta específica en el cerebro $^{66}$. El cerebro tiene propiedades viscoelásticas que permiten que se deforme durante el impacto ${ }^{26,92}$ y por ello tanto la velocidad como la duración del insulto traumático determinarán el grado del daño cerebral producido. Cuando las fuerzas que actúan sobre el cerebro lo hacen a gran velocidad, suelen causar un mayor daño porque el tejido es incapaz de absorber la fuerza lo suficientemente rápido. Sucede lo contrario cuando las fuerzas se aplican lentamente. Por otro lado, el cerebro es un órgano de estructura extremadamente compleja, macro- y microscópicamente, caracterizada por una enorme heterogeneidad tanto en orientación celular como en composición tisular, de lo que resulta una muy diferente repuesta viscoelástica de cada estructura frente a un impacto, dependiendo de la dirección e intensidad del mismo. Por esta razón se están comenzando a desarrollar modelos computarizados que permiten reproducir de forma fiable y detallada la respuesta cerebral regional frente a un insulto traumático ${ }^{125}$.

Hay dos tipos principales de fuerzas que pueden ejercer un daño en el parénquima cerebral: las fuerzas estáticas y las dinámicas. Las fuerzas estáticas actúan lentamente, durante un tiempo superior a $200 \mathrm{~ms}$, y de forma directa sobre el cráneo. Su efecto sólo dependerá de su amplitud y duración, y por lo tanto estará determinado exclusivamente por la energía cinética que el objeto productor del trauma transmita con su movimiento sobre la cabeza y que será absorbida por el cuero cabelludo, cráneo y encéfalo. Este tipo de fuerzas son muy poco frecuentes en la práctica clínica. Un ejemplo de modelo estático de traumatismo es el aplastamiento de una zona del cráneo al quedar atrapada la cabeza bajo un coche. Las fuerzas estáticas no causan lesiones cerebrales hasta que no se produce un grado determinado de deformación del parénquima cerebral.
Respecto a las fuerzas dinámicas, éstas actúan más rápidamente, durante un tiempo inferior a $200 \mathrm{~ms}$ y son las más frecuentes en el ámbito clínico. Su efecto no sólo dependerá de su amplitud y duración, sino también de su velocidad y aceleración. Las fuerzas dinámicas crean un movimiento rápido de la cabeza que determina tensiones en la propia estructura del cerebro. Por lo tanto, las fuerzas dinámicas además de transmitir energía cinética, que se absorbe por el cuero cabelludo, cráneo y encéfalo, van a producir un desplazamiento de la masa encefálica dentro del cráneo y un desplazamiento relativo de unas zonas del parénquima con respecto a otras. Han de diferenciarse las fuerzas dinámicas por impacto, cuya duración es menor de $50 \mathrm{~ms}$ y en las que hay contacto directo con la cabeza, de aquellas impulsivas, cuya duración es de 50-200 ms y en las que no hay contacto directo y el daño se produce exclusivamente por inercia.

El daño cerebral traumático más frecuentemente observado es el debido a fuerzas de inercia, por ejemplo cuando la cabeza se pone en movimiento de forma rápida (aceleración) o cuando se frena su movimiento de repente (deceleración). Cuando la aceleración es translacional (lineal), las lesiones tienden a localizarse en un área menor, mientras que cuando la aceleración es rotacional, se producen lesiones más dispersas en el cerebro. La mayoría de las lesiones que se observan en el ámbito clínico son debidas a una combinación de aceleración translacional y rotacional, lo que se conoce como aceleración angular.

\section{Tipos de daño cerebral traumático en humanos}

\section{a) Lesiones cerebrales focales versus lesiones difusas}

Tal y como hemos señalado en la introducción, existen dos grandes grupos de lesiones cerebrales post-traumáticas, las focales y las difusas (Figura 1). Las lesiones traumáticas cerebrales de tipo focal pueden ser secundarias tanto a los efectos directos del impacto como a las fuerzas de inercia, mientras que las lesiones difusas son siempre secundarias a movimientos de aceleración/deceleración de la cabeza ${ }^{1-3,72}$. Además, las lesiones cerebrales difusas tienden a producir una disfunción global de las funciones corticales y se asocian generalmente a un peor pronóstico neurológico que las lesiones focales.

Las lesiones cerebrales post-traumáticas de tipo focal que se producen con mayor frecuencia son las contusiones superficiales (con la pía intacta) y las laceraciones (con la pía rasgada) que pueden acompañarse de fracturas de cráneo y/o de hematomas intracraneales ${ }^{42}$. Las contusiones y laceraciones cerebrales pueden ser debidas a un trauma directo, por el choque del tejido cerebral bajo el área del impacto craneal, o ser causadas por un mecanismo de contragolpe, en un área lejana a la zona del impacto. Las contusiones subyacentes a la zona del impacto se deben a una fractura y/o deformidad del cráneo que impacta 


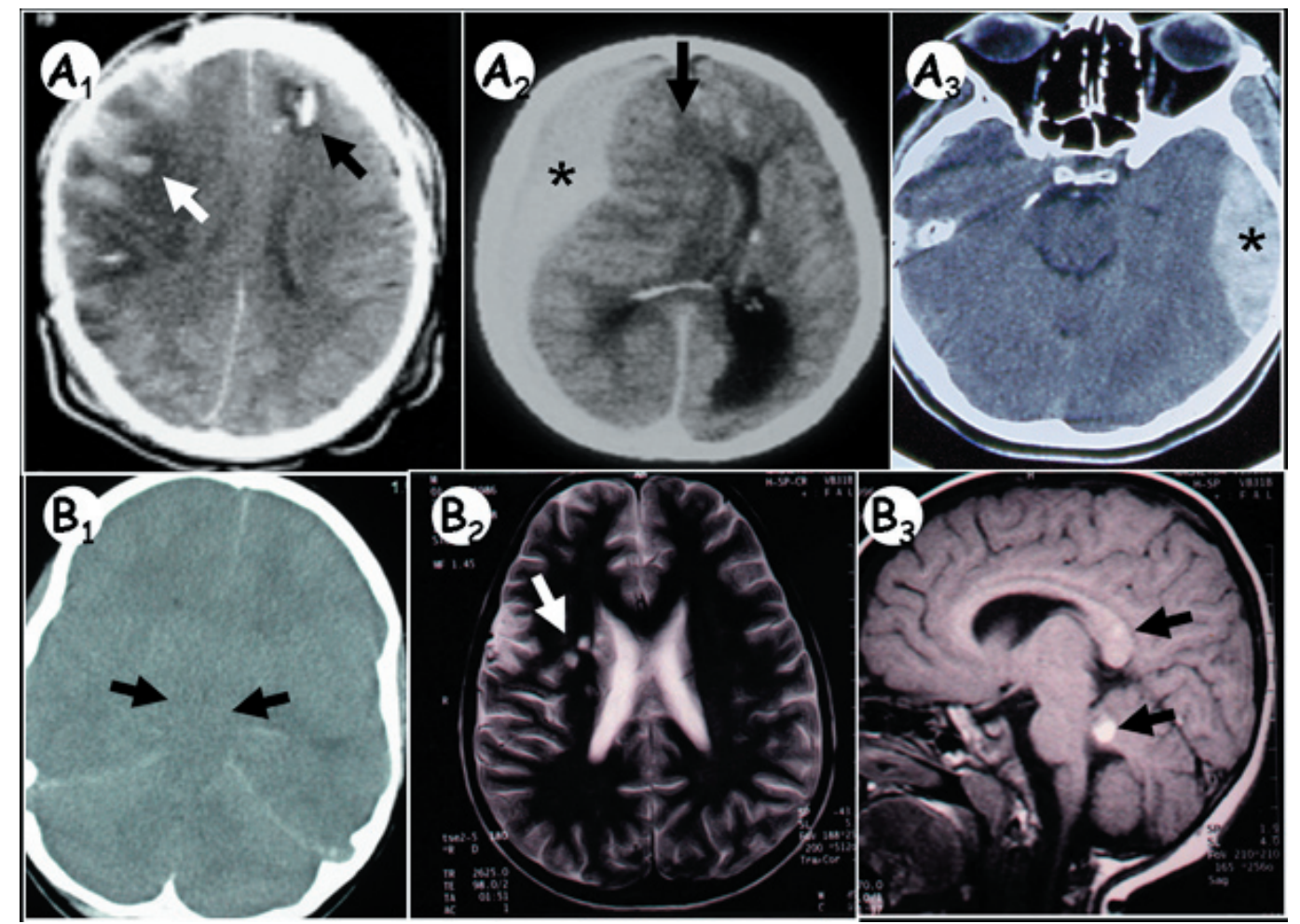

Figura 1. Tipos de lesiones cerebrales post-traumáticas agudas observadas en los estudios de neuroimagen. A-Estudios de TC con cortes axiales mostrando lesiones intracraneales de tipo focal: A1-Contusiones hemorrágicas rodeadas de edema perilesional y localizadas a nivel fronto-parietal derecho (flecha blanca) y frontal izquierdo (flecha negra); A2- Hematoma subdural agudo frontoparietal derecho (*) con desplazamiento de línea media (flecha negra); A3- Hematoma epidural temporal izquierdo (*); B- Estudios de TC y RM mostrando lesiones de tipo difuso: B1- TC, corte axial en el que se observa edema o swelling cerebral difuso con borramiento de cisternas basales (flechas negras); B2- RM potenciada en T2, corte axial, con lesión axonal difusa a a nivel de corona radiata derecha (flecha blanca); B3- RM potenciada en T1, corte sagital, con lesión axonal difusa a nivel de vermis cerebeloso y cuerpo calloso (flechas negras).

contra la superficie cerebral, excediéndose la capacidad de deformación elástica de la pía, vasos y tejido cortical. Sin embargo, las contusiones por contragolpe, en áreas remotas a la zona del impacto, se deben a mecanismos de aceleración/deceleración ${ }^{45}$. Si la deformación craneal en la zona del impacto excede su elasticidad máxima, el hueso se fractura ${ }^{69}$. El riesgo de que se produzca una fractura depende tanto del tamaño del objeto que impacta como del grosor del cráneo donde se produce. El riesgo es mayor cuanto menor es el tamaño del objeto, pues mayor será la concentración de energía y mayor el riesgo de penetración del mismo. Respecto a los hematomas extra-axiales, son causados por un daño vascular directo debido al impacto. El tipo de hemorragia más frecuentemente asociada a un TCE es la hemorragia subaracnoidea, por rotura de vasos en el espacio subaracnoideo. Los hematomas subdurales se producen por rotura de las venas puente entre el cerebro y la duramadre ${ }^{45}$. Los hematomas epidurales suelen producirse por la laceración de ramas de la arteria meníngea media debido a la fractura de la escama temporal, y/o por sangrado venoso originado en fracturas del diploe craneal, formándose un hematoma que va despegando la duramadre del cráneo. Cuando el trauma es grave pueden asociarse diferentes lesiones focales. Como veremos más adelante, los principales modelos que reproducen lesiones focales son los modelos de percusión lateral por fluido (Lateral Fluid Percussion), de impacto cortical controlado (Controlled Cortical Impact) y de caída de un peso sobre el cráneo ${ }^{41}, 45$ (Tabla 1).

Las lesiones cerebrales post-traumáticas difusas son muy frecuentes en la práctica clínica debido al desplazamiento que sufre la cabeza con respecto al cuello en la mayoría de los accidentes de tráfico. El cambio de velocidad de desplazamiento en el tiempo (aceleración-desaceleración) es un parámetro muy importante en la respuesta tisular secundaria al trauma. Las fuerzas de inercia producen un movimiento rápido de la cabeza que determina una distribución desigual de las tensiones dentro del cerebro, lo que causará una distorsión y estiramiento del tejido cerebral $^{41}$. Se pueden diferenciar dos tipos de lesiones difusas: 
TABLA 1

Relación de los principales modelos experimentales de traumatismo craneoencefálico

\begin{tabular}{|c|c|c|c|}
\hline \multirow[t]{30}{*}{ IN VIVO } & \multicolumn{2}{|c|}{ Modelos animales de Daño Cerebral Traumático Focal } & Autor, Año \\
\hline & \multirow{3}{*}{\multicolumn{2}{|c|}{ Modelo de daño criogénico }} & Klatzo, 1958 \\
\hline & & & James, 1990 \\
\hline & & & Todd, 1993 \\
\hline & \multicolumn{2}{|c|}{ Caida de un peso sobre el cráneo } & Feeney, 1981 \\
\hline & \multicolumn{2}{|c|}{ Percusión lateral por fluído, Lateral Fluid Percussion (LFP) } & McIntosh, 1989 \\
\hline & \multirow{4}{*}{\multicolumn{2}{|c|}{$\begin{array}{l}\text { Impacto cortical controlado, Controlled Cortical Impact } \\
\text { (CCI) }\end{array}$}} & Nilsson, 1977 \\
\hline & & & Lighthall, 1988 \\
\hline & & & Shapira, 1988 \\
\hline & & & Dixon, 1991 \\
\hline & \multirow{4}{*}{\multicolumn{2}{|c|}{ Inflado de balón }} & Langfitt, 1966 \\
\hline & & & Marshall, 1969 \\
\hline & & & Miller, 1973 \\
\hline & & & Yamaguchi, 1976 \\
\hline & \multicolumn{3}{|c|}{ Modelos animales de Daño Cerebral Traumático Difuso } \\
\hline & \multirow{4}{*}{\multicolumn{2}{|c|}{ Aceleración por inercia }} & Gennarelli, 1983 \\
\hline & & & Ross, 1994 \\
\hline & & & Anderson, 2003 \\
\hline & & & Gutierrez, 2001 \\
\hline & \multicolumn{2}{|c|}{ Impacto-aceleración por caída libre de peso } & Marmarou, 1994 \\
\hline & \multicolumn{2}{|c|}{ o Modelo de Marmarou } & Foda, 1994 \\
\hline & \multirow{2}{*}{\multicolumn{2}{|c|}{$\begin{array}{l}\text { Impacto-aceleración por aire comprimido } \\
\text { o Modelo de Cernak }\end{array}$}} & Cernak, 2004 \\
\hline & & & \\
\hline & \multicolumn{3}{|c|}{ Modelos animales de Daño Cerebral Mixto: Trauma + Daño secundario } \\
\hline & \multirow[t]{5}{*}{ Tipo de daño secundario } & Hipoxia & Clark, 1997 \\
\hline & & & Bramlett, 1999 \\
\hline & & & Beaumont, 2002 \\
\hline & & Hipotensión & Ishige, 1987 \\
\hline & & & Yamamoto, 1999 \\
\hline & \multicolumn{2}{|c|}{ Modelos animales de Conmociones por repetición } & Weber, 2007 \\
\hline \multirow[t]{7}{*}{ IN VITRO } & \multirow{2}{*}{\multicolumn{2}{|c|}{ Modelo de arañado/rasgado }} & Epstein, 1971 \\
\hline & & & Tecoma,1989 \\
\hline & \multicolumn{2}{|l|}{ Compresión por caída de peso } & Church, 2005 \\
\hline & \multirow[t]{4}{*}{ Estiramiento celular } & & Cargill, 1995 \\
\hline & & & Morrison, 1998 \\
\hline & & & Pfister, 2003 \\
\hline & & & Lusardi, 2004 \\
\hline
\end{tabular}

la lesión axonal difusa (LAD) y el swelling cerebral difuso. Las fuerzas mecánicas iniciales del trauma pueden lesionar directamente los axones ${ }^{77,90}$ mientras que el edema cerebral difuso suele ser máximo entre el tercer y quinto día tras el TCE. La LAD se debe a la lesión de los axones por el trauma, que produce un fallo en el transporte axonal ${ }^{96}$.
Cuando la intensidad del trauma es leve se observa un swelling axonal que sólo produce una disfunción de la conducción nerviosa, mientras que si es moderada o severa, se produce un estiramiento y daño estructural de los axones con desconexión axonal ${ }^{90}$. Aunque los estudios de TC no muestran alteraciones significativas, los estudios 
de Resonancia Magnética (RM) ponen de manifiesto pequeñas lesiones con forma ovoideas en relación con el edema y/o hemorragia secundarias al daño de las vainas axonales, típicamente a nivel de la corona radiata o cuerpo calloso. Respecto a la hinchazón del cerebro o swelling cerebral, estudios recientes realizados en un modelo experimental puro de lesión difusa han puesto en evidencia la importancia de los osmolitos cerebrales en su desarrollo ${ }^{86}$. Los modelos experimentales que reproducen este tipo de daño incluyen los modelos por impacto-aceleración ${ }^{20,73}$ (Tabla 1).

\section{b) Daño cerebral primario versus secundario}

La muerte celular secundaria a un TCE es el principal factor subyacente a los déficits neurológicos que se observan tanto en las lesiones cerebrales focales como en las difusas, y depende tanto de mecanismos primarios como secundarios ${ }^{35}, 119$. El daño primario es el resultado directo de las deformidades mecánicas que suceden en el momento del trauma e incluye las fracturas craneales, las contusiones y/o laceraciones cerebrales y la LAD. El daño secundario, aunque también se inicia con el evento traumático primario, se manifestará tras un período de horas o días e incluye el edema cerebral, los hematomas intracraneales y las lesiones por hipoxia/isquemia ${ }^{1,2,3}$. El daño secundario más importante, por su morbimortalidad asociada, es el edema o swelling cerebral difuso ${ }^{116}$ para el que no se han desarrollado terapias específicas útiles en la actualidad. Por último, se conoce como daño cerebral terciario al que define todos los fenómenos bioquímicos complejos a nivel celular y subcelular que se desencadenan tras el traumatismo inicial y que contribuyen a la aparición de las lesiones secundarias. Dentro de este último se incluyen las alteraciones en la función de los neurotransmisores, la pérdida de la integridad de las membranas celulares, los cambios en la homeostasis iónica y las alteraciones en diferentes vías metabólicas. La división entre daños primario y secundario tras un TCE, aunque artificial pues las alteraciones fisiopatológicas del TCE se interrelacionan de un modo dinámico, puede resultar de utilidad desde el punto de vista terapéutico. Las dianas terapéuticas en el TCE serán aquellas capaces de interrumpir o limitar los fenómenos y las cascadas bioquímicas que conducen al daño cerebral secundario.

\section{Diseño de modelos experimentales de TCE}

El diseño de un modelo experimental de TCE supone un reto para los investigadores. Los modelos experimentales de TCE tratan de reproducir las lesiones cerebrales traumáticas observadas en la práctica clínica y este daño debe poder cuantificarse y ser reproducible entre diferentes investigadores ${ }^{111}$. Un modelo es adecuado cuando cumple los siguientes criterios: (I) la fuerza mecánica usada para inducir el daño es controlable y cuantificable; (II) la lesión cerebral es reproducible y simula adecuadamente la observada en el daño cerebral humano y (III) existe un rango de gravedad del daño (leve, moderado, grave) que puede medirse con parámetros morfológicos, fisiológicos, bioquímicos o de conducta. Actualmente la mayoría de los estudios usan protocolos estándar que incluyen el uso de animales sham (sin daño) a los que se les realiza todo el procedimiento quirúrgico excepto el trauma y que sirven para controlar el efecto en las variables sistémicas de la anestesia, la técnica quirúrgica o la sujeción de la cabeza en un marco estereotáxico.

La presencia conjunta de lesiones focales y difusas en un mismo paciente se opone a la necesidad de desarrollar un modelo de TCE consistente, fiable y reproducible en el laboratorio. Por ello, una limitación importante de los modelos experimentales de TCE es la incapacidad de reproducir la heterogeneidad del daño observado en la práctica clínica. Inevitablemente el investigador escoge aquellos componentes del daño observado en los pacientes que desea estudiar en el laboratorio. Por lo tanto, la elección de un modelo específico en un proyecto de investigación dependerá del objetivo del estudio. Pese a sus limitaciones, los modelos experimentales suponen la mejor herramienta para ampliar nuestro conocimiento sobre el daño cerebral traumático y poder desarrollar terapias específicas.

Los modelos desarrollados en monos y cerdos reproducen fielmente la complejidad de las lesiones cerebrales post-traumáticas observadas en clínica por las similitudes anatómicas existentes con el cerebro humano ${ }^{100}$. Sin embargo, aunque son modelos científicos muy valiosos desde el punto de vista de la información que proporcionan, su uso en la mayoría de los laboratorios es insostenible debido al alto coste que suponen, tanto a nivel de la sofisticada infraestructura técnica que requieren como por el difícil manejo de los animales dado su gran tamaño. Actualmente, debido a las limitaciones tanto éticas como económicas para el uso de estos animales, son los modelos con roedores los más usados en la investigación del neurotrauma in vivo. Trabajar con roedores, animales de pequeño tamaño y bajo coste, permite realizar estudios que precisan un número de experimentos relativamente elevado, como los que analizan alteraciones morfológicas, bioquímicas, celulares o de conducta.

Con el objetivo de estudiar las lesiones cerebrales causadas por traumas no penetrantes, se desarrollaron inicialmente modelos que pretendían valorar los efectos de la presión en el cerebro ${ }^{29}$, como el modelo de "conmociónpercusión" ${ }^{\prime 4}$. Posteriormente, se desarrolló uno de los modelos de TCE focal que más se sigue empleando en la actualidad, conocido como "modelo de percusión lateral por fluido" (lateral fluid percussion, LFP), en el que se aplica una presión directa sobre el cerebro, previamente 
expuesto, utilizando para ello bien un pulso de aire o uno de agua ${ }^{31,101,107}$. Una técnica más reciente fue reproducir la deformación directa del cerebro con un dispositivo sólido, conocido como "modelo de impacto cortical controlado" (controlled cortical impact, $C C I)^{68}$. La principal ventaja del modelo $C C I$ con respecto al modelo de $L F P$, es que permite cuantificar más exactamente el impacto y por ello tener un mayor control sobre el daño causado, siendo probablemente el modelo de TCE focal más utilizado actualmente.

Sin embargo, entre todo el espectro de lesiones cerebrales post-traumáticas observadas en la práctica clínica, la respuesta precoz de edema o swelling cerebral difuso, junto con la LAD, son las dos lesiones más importantes para determinar el pronóstico de los pacientes que han sufrido un $\mathrm{TCE}^{57,88,118}$. Por esta razón, se desarrollaron los modelos de daño cerebral traumático difuso. Las lesiones post-traumáticas difusas son generalmente secundarias a fuerzas de inercia, las cuáles describen el movimiento de los objetos. La aceleración (variación de la velocidad respecto al tiempo) es un parámetro fundamental para determinar el daño del parénquima cerebral. Según la segunda Ley de Newton (Fuerza = masa $x$ aceleración), aceleraciones mayores corresponderán a fuerzas mayores. Estudios pioneros realizados por Ommaya et al. demostraron que la aceleración umbral necesaria para causar un daño aumenta rápidamente al disminuir la masa cerebral ${ }^{85}$. Por lo tanto, los modelos de daño por aceleración son más fáciles de desarrollar en animales con una cabeza de mayor tamaño, como son los monos y $\operatorname{cerdos}^{42,80}$. Sin embargo, debido al alto coste y más difícil manejo de estos animales, se han desarrollado en la última década modelos de daño difuso en roedores $^{20,21,47,73}$. El inconveniente de los modelos de daño difuso en roedores es que debido a la gran fuerza que es necesario aplicar sobre el cráneo para generar la aceleración suficiente sobre el cerebro, pueden producirse lesiones por deformación del cráneo junto con las propias lesiones difusas ocasionadas con la aceleración del impacto.

La necesidad de desarrollar modelos de TCE in vitro surgió hace varias décadas por la dificultad de interpretar las respuestas celulares en los modelos animales. Aunque los modelos in vivo proporcionan una representación anatómica y funcional más similar a la situación clínica, los modelos in vitro permiten tener un control más preciso de los daños tisulares.

\section{Modelos experimentales de TCE in vivo}

Expondremos en primer lugar los modelos que reproducen fundamentalmente lesiones focales y a continuación los que reproducen una lesión predominantemente difusa (Tabla 1). Puesto que el objetivo de los modelos animales es conseguir que la lesión inducida sea reproducible y que haya una mínima variabilidad, se deben monitorizar y controlar estrictamente todas las variables fisiológicas que puedan modificar el efecto un daño cerebral traumático y que por lo tanto pueden influir en la lesión tisular final. Las variables que se deben mantener dentro del rango normal a lo largo de todo el experimento son la temperatura, presión arterial, glucemia y gases arteriales. Por supuesto, todos los animales incluidos en un estudio experimental deben ser del mismo sexo y pertenecer al mismo grupo de edad.

\section{Modelos de daño cerebral focal}

Las principales lesiones cerebrales de tipo focal que se observan en la práctica clínica tras sufrir un TCE son las contusiones cerebrales. Los modelos animales más empleados en el laboratorio que reproducen lesiones cerebrales post-traumáticas de tipo focal son el modelo de daño criogénico, el modelo de caída de un peso sobre el cráneo, el modelo de lateral fluid percussion (LFP), el de controlled cortical impact (CCI) y, finalmente, el modelo de inflado de balón. Presentaremos de forma más detallada los dos modelos más frecuentemente empleados en los trabajos de investigación, los de $L F P$ y $C C I$.

\section{Modelo de daño criogénico}

Este modelo consiste en la aplicación de un fluido frío $0^{55}$ o de una barra metálica enfriada con nitrógeno líquido ${ }^{116}$ sobre la superficie expuesta del cerebro. El modelo de daño criogénico induce una lesión cortical por enfriamiento local del cerebro ${ }^{59}$ consistente en un foco necrótico rodeado de vasos con una permeabilidad aumentada por la rotura de la barrera hematoencefálica (BHE) $)^{94}$. Actualmente se considera que este modelo reproduce exclusivamente un edema vasogénico puro y que no es realmente un modelo de TCE, pues las lesiones que produce no se correlacionan directamente con ninguna de las observadas en pacientes que han sufrido un trauma craneal ${ }^{34}$.

\section{Modelo de caída de un peso sobre el cráneo}

En este modelo se utiliza la fuerza gravitatoria de la caída libre de un peso para producir un daño cerebral focal ${ }^{36}$. Una vez expuesto el cráneo se coloca la rata en la parte inferior del impactador. Se recomienda inmovilizar la cabeza del animal antes de producir el impacto, para asegurar la reproducibilidad del modelo entre laboratorios. La intensidad del trauma se puede ajustar en función de la altura desde la que se deja caer el peso. Cuando la intensidad del trauma es leve se observa una pérdida celular en la corteza subyacente a la zona del impacto, así como daño bilateral cortical e hipocampal ${ }^{110}$. Cuando la intensidad es grave, se producen lesiones focales que simulan las contusiones observadas en pacientes ${ }^{97}$.

La ventaja de este modelo es que es muy sencillo y rápido de realizar. Sin embargo, la frecuencia de fracturas 


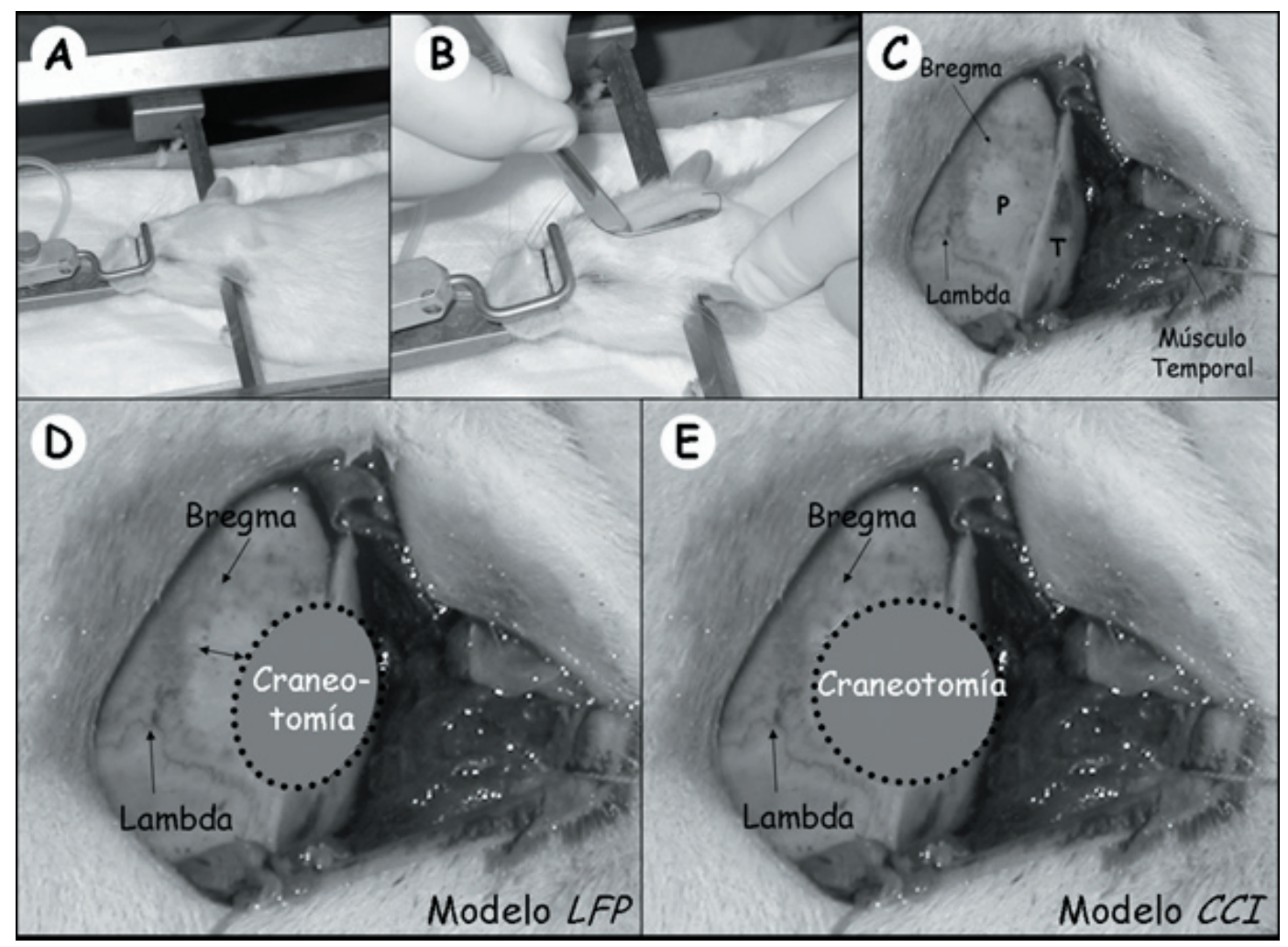

Figura 2. Exposición del cráneo para la realización de una craneotomía en la rata. A- La rata se coloca en un marco estereotáxico. B- Se realiza una incisión en piel con forma de " $U$ " dirigida hacia el lado donde se va a realizar la craneotomía. C-Se diseca subperiósticamente el músculo temporal, quedando expuestas la sutura sagital, bregma y lambda. D- En el modelo de percusión lateral por fluído se realiza una craneotomia a una distancia determinada de la línea media (ver texto) sobre la que se cementará un tapón de plástico. E- En el modelo de impacto cortical controlado se realizará un craneotomía de $1 \mathrm{~cm}$ de diámetro que tiene como límite anterior la sutura bregmática; límite posterior, sutura lambdoidea; límite medial, sutura sagital; y como límite lateral, la base de la escama temporal. LFP = Lateral Fluid Percussion (percusión lateral por fluído). CCI = Controlled Cortical Impact Injury (impacto cortical controlado).

craneales es muy alta cuando la intensidad del trauma es alta. Además, hay riesgo de que se produzca un daño asociado por rebote, como en todos los modelos de caída libre de peso por gravedad. En general, no es un modelo muy usado en la actualidad por la variabilidad inter-animal e inter-investigador existente.

\section{Modelo de percusión lateral por fluido -Lateral Fluid Percussion (LFP)-}

Es un modelo de daño cerebral directo por deformación, que trata de reproducir las contusiones cerebrales observadas en los pacientes que han sufrido un TCE. El daño cerebral traumático se induce liberando un péndulo que impacta una columna de fluido sobre la superficie dural intacta, que ha sido expuesta previamente mediante una pequeña craneotomía ${ }^{114}$. El impacto del fluido sobre la corteza produce un desplazamiento del cerebro que determina fuerzas de tensión en el tejido cerebral, tratándose de un modelo de mecánica compleja. Los primeros modelos de percusión por fluido, desarrollados en gatos y conejos $^{49,103}$ y posteriormente en ratas ${ }^{30,78}$, consistían en la aplicación de un impacto sobre la línea media del cerebro. Posteriormente la localización del impacto fue modificada, para producir un daño focal en un solo hemisferio, denominándose modelo de $L F P^{79}$. Desde entonces, el modelo $L F P$ se ha usado extensivamente en las investigaciones del daño cerebral traumático siendo uno de los modelos de lesión focal más empleados.

Para realizar este modelo, los animales anestesiados se sitúan en un marco estereotáxico. Se realiza una incisión en la piel con forma de "U" sobre el vértex en línea media, extendiéndola hacia la región temporal ipsilateral (Figura 2). Se diseca subperiósticamente el músculo temporal y se realiza una craneotomía pequeña para cementar en el cráneo un tapón de plástico sobre la duramadre intacta. El dispositivo de impacto de este modelo consiste en un cilindro de Plexiglas relleno con suero salino isotónico estéril. Un extremo del cilindro incluye un transductor que se conecta 


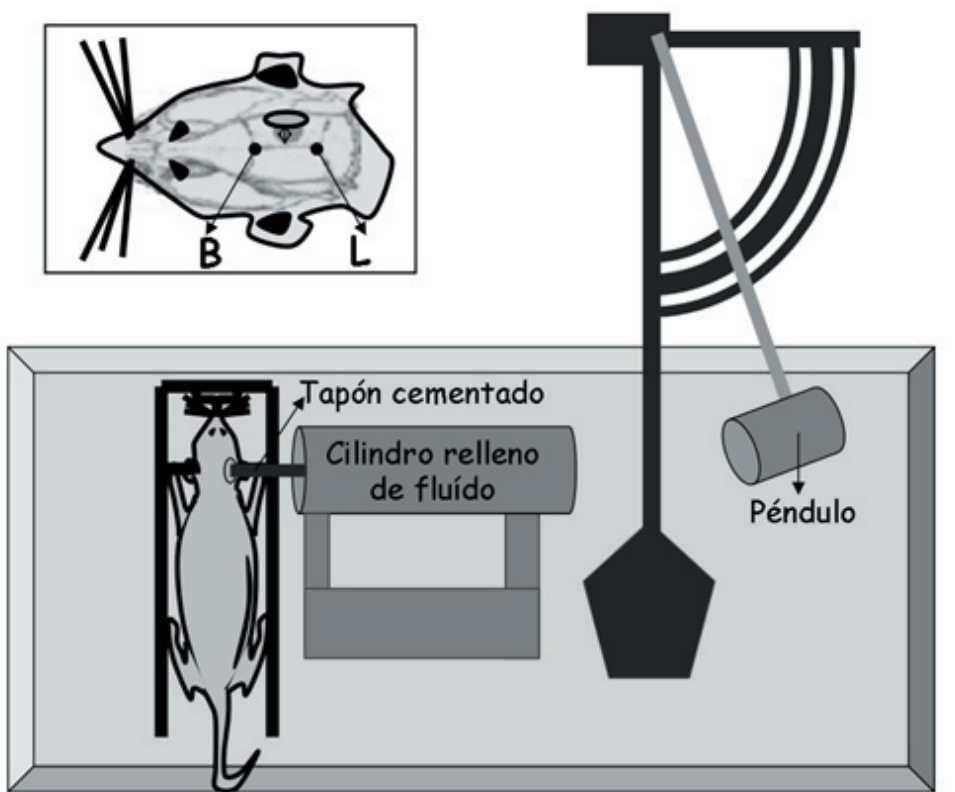

Figura 3. Modelo de percusión lateral por fluido, -LFP-. Esquema que representa el modelo de percusión lateral por fluido y la localización de la craneotomía. Una vez colocada la rata en un marco estereotáxico, se realiza una craneotomía parieto-temporal derecha a una distancia determinada de la linea media (ver texto). A continuación se impacta un péndulo desde una altura determinada en un cilindro lleno de suero salino, haciendo golpear un bolo de fluido sobre el cerebro del animal expuesto. $B=b r e g m a$, $L=l a m b d a$. a un tubo que se adaptará al tapón cementado en el cráneo en el momento de la cirugía. En el otro extremo del cilindro se coloca un péndulo que generará un pulso de presión sobre el fluido contenido dentro del tubo y que deformará el cerebro inmediatamente bajo la duramadre expuesta (Figura 3). La intensidad del trauma causado dependerá de la presión ejercida con el pulso de fluido ${ }^{79,113}$.

A lo largo de los años se han ido realizando modificaciones sobre el modelo original, consistentes en cambios en la localización de la craneotomía o el ángulo de incidencia de la percusión, las cuáles han determinado los distintos tipos y grados de lesión observados en los diferentes laboratorios. La localización de la craneotomía en este modelo es un factor determinante del tipo de daño cerebral causado y al que por tanto se debe prestar especial atención. Según la descripción original, el modelo consiste en la realización de una craneotomía de $4.8 \mathrm{~mm}$ de diámetro centrada en el hueso parietal, $4 \mathrm{~mm}$ lateral a la sutura sagital ${ }^{79}$. Se ha observado que si la craneotomía se sitúa a menos de $3.5 \mathrm{~mm}$ de la sutura sagital, se produce un daño en ambos córtex, ipsilateral y contralateral a la percusión, que es observable tanto en los estudios convencionales histológicos como en las imágenes de resonancia magnética. Sin embargo, si la craneotomía se realiza a más de $3.5 \mathrm{~mm}$ de la sutura sagital, no se observan lesiones en la corteza contralateral $^{118}$.

Respecto a la respuesta fisiológica tras el impacto, se observa un aumento transitorio de la presión arterial, una pausa de apnea breve, aumento de la presión intracraneal y aumento inmediato del flujo sanguíneo cerebral, seguido de una reducción del mismo que dura al menos 4 horas tras el impacto ${ }^{124}$. Aunque el objetivo inicial de este modelo fue generar una lesión por golpe-contragolpe en un animal pequeño, se trata realmente de un modelo de daño mixto, que asocia lesiones tanto de tipo focal como difuso ${ }^{12,28,44,50,52}$. El principal hallazgo neuropatológico observado consiste en una contusión cortical a nivel del sitio del impacto en la interfase entre sustancia gris y blanca, que llegará a convertirse en una cavidad necrótica pasadas unas semanas del traumatismo ${ }^{28,44}$. Además se observan hemorragias petequiales en el parénquima cerebral (que pueden variar desde pequeños focos hemorrágicos dispersos a áreas hemorrágicas confluentes), lesión axonal difusa bilateral $^{17,18}$, hemorragia subaracnoidea y muerte celular a nivel de la corteza, hipocampo y tálamo ipsilateral ${ }^{17,18,27,28,50,99}$.

Las principales ventajas de este modelo son su alta reproducibilidad y la capacidad de producir un daño cerebral de diferente grado de severidad según la intensidad del trauma ${ }^{30,31}$. Además puede emplearse con ratones, permitiendo la investigación en animales knockouts o con hiper-expresión de un gen particular ${ }^{17}$. La principal desventaja del modelo $L F P$ y que limita su utilidad, es que al aumentar la intensidad del impacto éste afecta de forma desproporcionada el tronco cerebral, lo que puede conducir al desarrollo de edema pulmonar neurogénico y a una elevada mortalidad (50\%). Por otro lado, el control biomecánico es limitado y complejo de realizar ${ }^{114}$, determinando una variabilidad significativa en el daño producido.

\section{El modelo de impacto cortical controlado, -Controlled Cortical Impact (CCI)-}

Este modelo también trata de reproducir las contusiones cerebrales post-traumáticas observadas en la práctica clínica. La principal diferencia entre el modelo $L F P$ y 


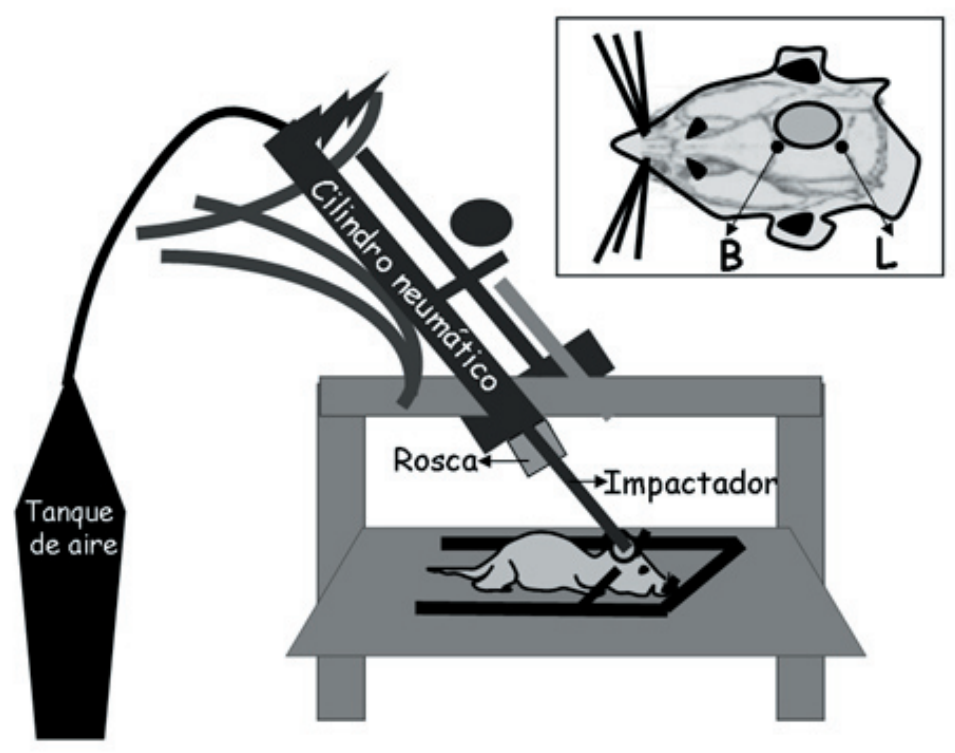

Figura 4. Modelo de impacto cortical controlado, CII-. Esquema que representa el modelo de impacto cortical controlado y la localización de la craneotomía. Una vez colocada la rata en un marco estereotáxico, se realiza una craneotomía parieto-temporal derecha que tiene como límite anterior la sutura bregmática y posterior la lambdoidea. El trauma se inducirá al hacer golpear un impactador, que está conectado a un cilindro neumático mediante un sistema roscado, sobre el cerebro del animal. $B=$ bregma, $L=$ lambda.

el modelo $C C I$ es que en este último se reproduce de un modo más exclusivo una lesión cerebral post-traumática de tipo focal. El daño cerebral traumático se produce usando un impactador sólido que libera energía mecánica sobre el cerebro con la duramadre íntegra ${ }^{32,68,84,97}$. Tras realizar una craneotomía (Figura 2), se utiliza aire presurizado para generar la energía mecánica necesaria para deformar el cerebro del animal, que tiene la cabeza sujeta en un marco estereotáxico. El dispositivo consiste en un cilindro neumático conectado, generalmente, con un sistema de rosca a un impactador de 4 a $5 \mathrm{~cm}$ de longitud y $1 \mathrm{~cm}$ de diámetro (Figura 4). La intensidad del trauma depende principalmente de la profundidad de la deformación y de la velocidad del impactador ${ }^{32}$.

La profundidad de la deformación cortical que se quiere producir se ajusta en la conexión roscada entre el cilindro y el impactador y varía entre 1 y $3 \mathrm{~mm}$. La velocidad de impacto empleada en la mayoría de los estudios es de 0.5 a $10 \mathrm{~m} / \mathrm{s}$. Finalmente, la duración del impacto puede variar entre 25 a $250 \mathrm{~ms}$. Una vez realizado el trauma se recomienda reponer la ventana craneal realizada, con cera de hueso, para evitar el efecto de la descompresión ósea sobre la evolución del daño cerebral.

Respecto a la respuesta fisiológica frente al impacto, se produce un aumento de la presión intracraneal, disminución de la presión arterial y de la presión de perfusión, así como un período de coma variable. El modelo de CCI determina fundamentalmente un área de necrosis focal en la corteza, rodeada de un área edematosa que va creciendo progresivamente, reproduciendo todo el espectro de lesiones cerebrales contusivas en humanos ${ }^{32,68}$. Sin embargo, la alteración neuropatológica es realmente más difusa e incluye además del daño cortical, pérdida de células en hipocampo, giro dentado y tálamo ipsilateral que se puede extender al hemisferio contralateral cuando la intensidad del impacto es mayor ${ }^{43,48,98}$. Otras alteraciones anatomopatológicas asociadas son la lesión axonal a nivel de la sustancia blanca subcortical, cápsula interna, núcleos talámicos y tronco cerebral. Con este modelo, se ha demostrado que el edema asociado a las contusiones cerebrales es fundamentalmente de tipo celular ${ }^{60}$. Los estudios de difusión de RM han mostrado valores altos del Coeficiente de Difusión Aparente (CDA), indicativos de edema predominante en el compartimento intracelular ${ }^{107}$. Existe una fase breve y transitoria de apertura de la BHE en las primeras 8 horas tras el trauma, quedando completamente cerrada a las 24-48 $\mathrm{h}^{9}$.

La principal ventaja de este modelo es el mayor control de los parámetros mecánicos de deformación (tiempo, velocidad y profundidad del impacto) con respecto al modelo de LFP y por lo tanto es un modelo más reproducible. Además asocia una baja mortalidad debido a que no se produce deformación del tronco cerebral. También se puede usar en ratones, permitiendo la investigación sobre animales transgénicos. Su principal desventaja es que su grado de complejidad es moderado.

\section{Modelo de inflado de balón}

Es otro modelo de deformación del cerebro. Reproduce la compresión por una masa y el tipo de edema observado tras la evacuación de un hematoma intracraneal. Es importante resaltar que este modelo sólo estudia las alteraciones observadas justo tras la evacuación de la masa, pues no asocia lesiones difusas, que generalmente están presentes en el trauma clínico. Algunos autores proponen que el swelling o aumento de volumen hemisférico observado en este modelo se debe al aumento del volumen vascular 


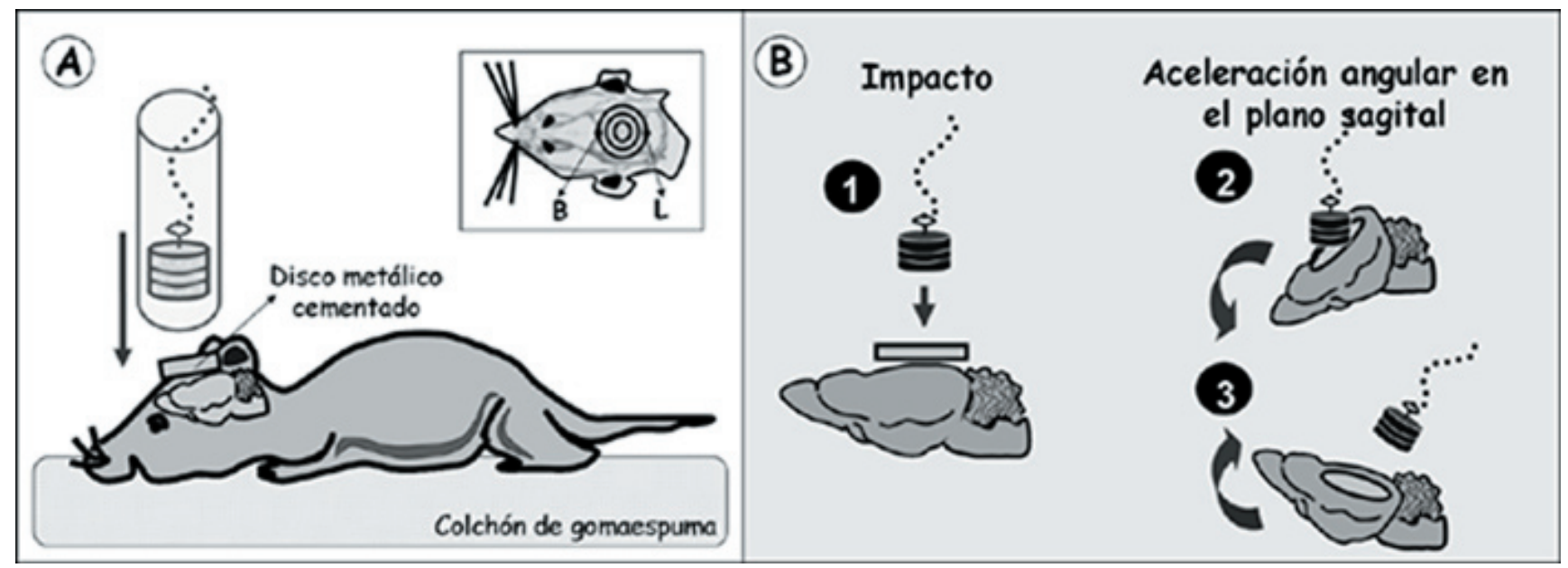

Figura 5. Modelo de impacto-aceleración por caída libre de peso. A- Esquema del modelo de impacto-aceleración de Marmarou. En primer lugar se coloca un disco metálico sobre el cráneo de la rata, centrado en línea media y entre bregma y lambda. A continuación se coloca el animal sobre una esponja y con la cabeza centrada bajo un cilindro de metacrilato por el que se deja caer una pesa para que golpee el disco metálico. B-La cabeza de la rata sufre un impacto seguido de una aceleración angular en el plano sagital.

o hiperemia, secundaria a vasoparálisis ${ }^{25,63,76}$, mientras que otros consideran que es principalmente debido al aumento del volumen de agua en las células o edema celular ${ }^{54,81,122}$.

\section{Modelos de daño cerebral difuso}

Las principales lesiones cerebrales de tipo difuso que se observan en la práctica clínica tras sufrir un TCE son la LAD y el edema o swelling cerebral difuso. Los principales modelos animales que reproducen un daño cerebral traumático de tipo difuso son los modelos de aceleracióndeceleración, el modelo de impacto-aceleración por caída libre de un peso y el modelo de impacto aceleración por aire comprimido.

\section{Modelos de aceleración-deceleración}

El movimiento del cerebro dentro del cráneo se considera que es el factor etiológico más importante del daño cerebral tras un TCE cerrado en humanos ${ }^{39}$. La aceleración de la cabeza produce una rotación y deformación del cerebro si la intensidad del impacto excede un cierto umbral. Se ha demostrado que la rotación rápida del cerebro es el principal mecanismo que conduce a una lesión cerebral difusa $^{51}$. Dentro de este grupo de modelos experimentales hay algunos en los que no se restringe el movimiento de la cabeza o sólo está restringido a nivel cervical y que por ello reproducen fielmente la aceleración-deceleración sufrida en los accidentes de tráfico. Sin embargo, la gran variabilidad en el tipo de daños cerebrales que causa, debida al limitado control de las fuerzas biomecánicas, ha favorecido el reciente desarrollo de modelos con restricción del movimiento y con menor variabilidad inter-animal. Como las fuerzas rotacionales necesitan un incremento de energía exponencial con respecto al tamaño del cerebro para producir el mismo daño, estos modelos se han desarrollado fundamente en monos $^{39}$, cerdos pequeños ${ }^{95}$, ovejas ${ }^{6}$ y conejos $^{47}$. Por ello actualmente son modelos experimentales poco útiles debido al alto coste y las técnicas sofisticadas que requieren los animales de gran tamaño.

Los estudios histopatológicos del daño cerebral causado por estos modelos muestra una LAD que afecta de forma amplia a la sustancia blanca y a la unión entre la sustancia blanca y la sustancia gris, así como pérdida neuronal en el córtex y daño bilateral de los hipocampos, estructuras que se sabe son muy vulnerables al daño traumático ${ }^{100}$.

\section{Modelo de impacto-aceleración por caída libre de un peso: modelo de Marmarou}

Este modelo se desarrolló en roedores para reproducir la lesión cerebral difusa que suele estar presente en pacientes que han sufrido un TCE grave tras un impacto cerrado sobre el cráneo $^{73}$. La mayor ventaja de este modelo es que reproduce un edema o swelling cerebral difuso así como una $\mathrm{LAD}$, sin asociar contusiones focales ni la rotura permanente de la $\mathrm{BHE}^{3,38,89}$. El dispositivo de impacto utilizado consiste en una pesa que se deja caer libremente por gravedad a través de un tubo de Plexiglas sobre un disco metálico fijado al cráneo de una rata que descansa sobre un colchón deformable de goma-espuma (Figura 5-A).

En este modelo, tras exponerse quirúrgicamente el cráneo de la rata, se pega sobre el mismo un disco metálico 
de $10 \mathrm{~mm}$ de diámetro y $3 \mathrm{~mm}$ de altura, centrado entre las suturas bregmática y lambdoidea. Sobre este disco metálico golpeará la pesa al caer. El objetivo de colocar este disco es que se distribuya la fuerza mecánica del impacto por todo el cráneo y de este modo se disminuya el riesgo de fracturas craneales y de lesiones focales. La cabeza del animal anestesiado se coloca, sin restricción de su movimiento y apoyada su superficie ventral sobre una esponja, de tal forma que la superficie dorsal de la cabeza quede debajo de la columna por la que caerá el peso. El colchón de goma-espuma sobre el que se apoya la rata tiene $10 \mathrm{~cm}$ de altura y una "constante de elasticidad" conocida (constante de elasticidad de 4-0, Tipo E de esponja; Ashland, VA) para permitir un determinado movimiento de la cabeza con el impacto (Figura 5-B). Las propiedades mecánicas de esta esponja son muy importantes para determinar tanto el tipo de daño como la gravedad del daño producido con este modelo. El impacto producirá una aceleración angular rápida en el plano sagital, que determina fundamentalmente fuerzas de estiramiento en el interior del cerebro responsables del daño cerebral. Este es uno de los pocos modelos en roedores que produce un coma postraumático, frecuentemente observado en los pacientes que han sufrido un TCE grave.

Con este modelo se pueden producir lesiones cerebrales de diferente intensidad dependiendo de la masa y la altura desde la que cae libremente la pesa ${ }^{73}$. Un impacto producido con una pesa de $450 \mathrm{~g}$ desde $2 \mathrm{~m}$ de altura se considera grave y está asociado a una mortalidad del $44 \%$ (en animales con ventilación espontánea) y a una incidencia de fracturas craneales de $12.5 \%$. Puesto que la muerte se debe a un fallo respiratorio, probablemente secundaria al fallo transitorio de las funciones del tronco cerebral, la mortalidad se reduce a un $10 \%$ cuando las ratas se ventilan mecánicamente. Sin embargo la mortalidad en la modalidad de TCE leve (caída de la pesa desde $1 \mathrm{~m}$ de altura) es muy reducida.

El principal hallazgo morfológico del daño traumático con este modelo es la LAD, fundamentalmente a nivel del cuerpo calloso, cápsula interna y tractos piramidales del tronco cerebral, junto con un aumento del tamaño de las prolongaciones astrocitarias que rodean los capilares cercanos, conocido como edema celular glial. Sin embargo, no se observan lesiones contusivas focales ${ }^{38,105,106}$. Así mismo, asocia una hemorragia subaracnoidea postraumática que será mayor conforme aumente la intensidad del impacto ${ }^{38}$. A nivel de la sustancia gris, el daño neuronal se identifica en el córtex supraventricular, justo subyacente a la zona del impacto así como en ambos hipocampos. La luz de los capilares corticales resulta comprimida por la hinchazón de las prolongaciones astrocitarias. La constricción de los capilares explica que el tratamiento consistente en aumentar la presión arterial sea útil para prevenir los episodios isquémicos en ese tipo de lesión traumática ${ }^{11}$. Diez días después de la lesión traumática, el swelling de los astrocitos ha desaparecido y el área de daño neuronal se sustituye por un área de gliosis reactiva. A nivel de la sustancia blanca, se observa un swelling axonal masivo, como resultado de un transporte axonal anterógrado enlentecido, que aparece a las $6 \mathrm{~h}$ del trauma y que también desaparece a los diez días después del mismo. En una fase crónica, a las cuatro o seis semanas tras el impacto, las ratas muestran ventriculomegalia.

Los estudios de gravimetría y flujo sanguíneo cerebral mostraron que el swelling cerebral se debe a un aumento del contenido de agua, es decir, se trata de un swelling por edema y no por hiperemia ${ }^{74}$. Estudios recientes de RM han confirmado estos hallazgos. Las imágenes de RM pesadas en $\mathrm{T} 1$ tras la administración de contraste (Gd-DTPA) han mostrado un aumento de la intensidad de la señal justo tras el trauma, debido a la disfunción aguda de la BHE que causa una extravasación del medio de contraste. La apertura de la BHE es muy precoz y transitoria, comenzando a cerrarse a los 15 minutos tras el TCE y recuperando su integridad funcional a los 30 minutos del trauma ${ }^{5}$. En los estudios de RM pesados en difusión se observa un comportamiento bifásico del CDA, con un aumento breve y transitorio de dicho coeficiente durante los primeros 30-60 minutos después del TCE, seguido de un descenso prolongado del CDA que comienza a los 45 minutos del daño y alcanza su valor mínimo a las $24 \mathrm{~h}$ tras el TCE, llegando a valores normales a los 7 días del trauma. Es decir, este modelo induce una primera fase, breve y transitoria en la que predomina el edema vasogénico y una segunda más prolongada y con más repercusión clínica en la que predomina el edema intracelular ${ }^{8,75}$. Las alteraciones del metabolismo cerebral estudiadas con la técnica de cromatografía líquida de alta eficiencia (High Performance Liquid Chromatography, HPLC) consisten en niveles disminuidos de ATP, de encimas nicotínicas (NAD+), de $\mathrm{N}$-acetil-aspartato y del ratio GSH/GSSG junto con aumento de los catabolitos derivados del ATP y aumento del metabolito ADP-ribosa. Estos hallazgos son compatibles con un aumento de la demanda energética, fallo mitocondrial y daño oxidativo ${ }^{93}$.

El modelo de impacto-aceleración diseñado por el Profesor Marmarou es un modelo muy popular porque es barato y fácil de realizar. Sin embargo, las variables biomecánicas del impacto producido con este modelo no están estrictamente controladas por el investigador. Por un lado, hay riesgo de sufrir un segundo impacto al rebotar la pesa, algo que se evita deslizando la rata sobre la esponja para desplazar la cabeza del animal fuera del tubo de Plexiglas, justo tras recibir el impacto. Además, cuando la pesa cae a través del tubo de Plexiglas se pueden producir desplazamientos laterales de la misma, lo que puede 
causar una lateralización del impacto y/o frenado de la pesa, determinando una variabilidad en la distribución e intensidad del impacto.

\section{Modelo de impacto-aceleración por aire comprimido o Modelo de Cernak}

Es un modelo desarrollado recientemente, muy similar al de Marmarou pero algo más complejo de realizar, que tiene como objetivo mejorar el control de las variables biomecánicas y aumentar la homogeneidad del daño cerebral producido ${ }^{20}$. El dispositivo utilizado consiste en un impactador de alta velocidad conducido por un chorro de aire que contacta con un disco metálico pegado al cráneo del animal. El animal se coloca sobre un gel de $1.7 \mathrm{~cm}$ con una compresibilidad de aproximadamente $64 \mathrm{kPa} / \mathrm{mm}$ que decelerará la cabeza del animal tras el impacto. Para asegurarse del contacto preciso con el disco metálico, el impactador de $14 \mathrm{~cm}$ de longitud puede bajarse manualmente sobre el disco de tal forma que las dos superficies se superpongan. Un haz de luz láser se usa para confirmar que las dos superficies son paralelas y que contactan entre sí. Una vez establecido el punto de contacto, el impactador se eleva a una distancia determinada sobre el disco. La distancia a la que el impactador viaja y la velocidad a la que se conduce determinan la intensidad del trauma, y ambas variables se hallan completamente bajo control por el investigador. La velocidad del impactador es constante, de $3.25 \mathrm{~m} / \mathrm{s}$. La gravedad del trauma dependerá de la distancia que el impactador avance una vez que contacta el disco.

Con este modelo también se ha observado en los estudios de desecación del cerebro y en las secuencias de difusión de RM que se produce un aumento del contenido de agua del cerebro localizado predominantemente en el espacio intracelular, que comienza a los 20 minutos y es máximo a las 24 horas después del trauma ${ }^{20}$. La principal ventaja de este modelo es que el control por el investigador de la velocidad y del tiempo durante el cual hay contacto con el disco, los factores biomecánicos más importantes para determinar el daño cerebral, es muy estricto. La principal desventaja de este modelo de daño difuso es que el dispositivo necesario para aplicar el trauma es más complejo y caro que el utilizado en el modelo de Marmarou.

\section{Modelos mixtos de daño primario y secundario}

La asociación de un daño secundario al traumatismo exacerba el daño traumático primario y empeora el pronóstico. La hipoxia, isquemia, hipovolemia e hipotensión son los principales insultos secundarios que se asocian al daño cerebral traumático en la práctica clínica ${ }^{22}$. Para valorar las consecuencias y mecanismos de actuación de los insultos secundarios tras un trauma se han creado modelos que combinan el daño cerebral traumático con insultos secundarios $^{104}$.

En los modelos conjuntos de TCE e hipoxia, una vez producido el trauma se somete a los animales a condiciones de hipoxia (pO2 de 30-40 mmHg o FiO2 del 10-13\%) $)^{10,13,24}$. En los modelos de TCE e hipotensión, se induce una hemorragia o se administran fármacos hipotensores para disminuir la presión arterial media a un valor entre 30 y $50 \mathrm{mmHg}^{53,123}$. En los modelos de daño mixto es importante establecer el tiempo durante el que se mantiene el insulto secundario y el momento tras el trauma en que se introduce dicho insulto. Es necesario mantener los episodios secundarios durante al menos un tiempo mínimo (valor umbral) para producir un daño asociado $^{4,62}$. Las condiciones de hipoxia se deben mantener durante 30 minutos y las de hipotensión durante 6 minutos como mínimo, para observar un aumento en la muerte celular en las regiones vulnerables ${ }^{12,53}$. Respecto al momento tras el trauma en el que comienza el daño secundario, se ha observado que si la isquemia se induce varias horas después del impacto, la cantidad de contusión cortical aumenta significativamente ${ }^{24}$.

La investigación sobre modelos mixtos de TCE e hipoxia/hipotensión es muy importante porque el $90 \%$ de los pacientes que fallecen tras sufrir un TCE grave presentan áreas de isquemia en el hipocampo y/o en los ganglios basales ${ }^{61}$. Se ha observado que la asociación de hipoxia y/o hipotensión arterial en animales sometidos a un TCE con el modelo de impacto-aceleración agrava el edema cerebral de forma significativa. El aumento del contenido de agua es del $1 \%$ en el grupo de animales sometidos a un daño mixto mientras que es de sólo el $0.5 \%$ en el grupo expuesto a un daño traumático exclusivo. De hecho, las imágenes de RM son compatibles con una rotura más prolongada de la BHE en los animales expuestos a un daño mixto ${ }^{58}$.

\section{Modelos experimentales de conmoción por repetición}

La conmoción cerebral postraumática se define como una alteración del estado mental inducido por un trauma, que puede asociar o no pérdida de conocimiento ${ }^{5}$. Los modelos de conmoción por repetición consisten en la aplicación de una agresión traumática inicial que se sigue de otras posteriores con el mismo o diferente grado de intensidad $^{121}$. Pese a su importancia clínica, pues el sometimiento a lesiones cerebrales traumáticas repetitivas sucede en un porcentaje significativo de niños víctimas de abusos y deportistas, se ha prestado escasa atención a este tipo de modelos hasta la última década. El daño cerebral repetitivo por múltiples traumas se ha asociado a un aumento de la vulnerabilidad del cerebro frente a un segundo impacto, que es mayor en los primeros 7-10 días 


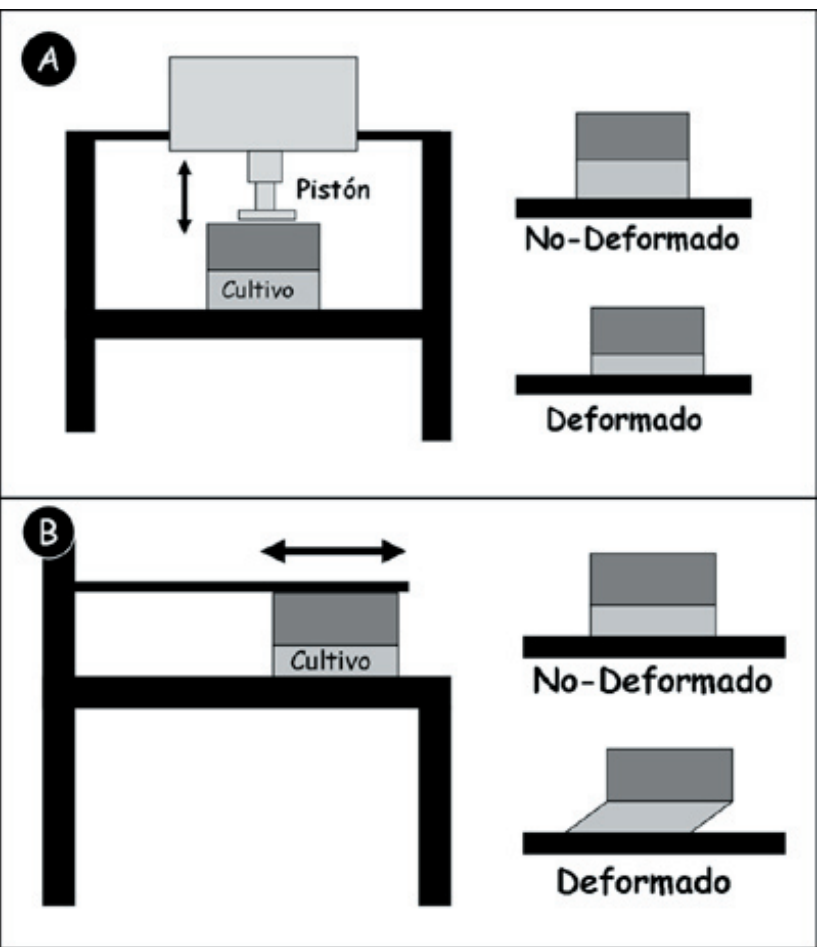

Figura 6. Modelos de daño traumático in vitro. Esquemas de dispositivos para producir deformaciones traumáticas sobre cultivos celulares u organotípicos. A- Modelo de compresión, en el que se aplica una compresión mecánica sobre el cultivo. B- Modelo de estiramiento, en el que se aplica una deformación por estiramiento en una sola dirección.

tras la primera conmoción postraumática ${ }^{16,46}$ así como al potencial desarrollo de déficits cognitivos crónicos, como por ejemplo la demencia pugilística en boxeadores ${ }^{56}$. De hecho, se ha observado que el número de conmociones es inversamente proporcional a los obtenidos en los test neuropsicológicos ${ }^{120}$.

En la mayoría de estos modelos por repetición del daño se aplican traumatismos de intensidad leve o moderada, pero no grave. Puesto que en la clínica el principal hallazgo de la exploración es la presencia de dificultades cognitivas, los animales sometidos a estos modelos se evalúan con tests de función cognitiva, como el test del laberinto de agua de Morris, además de los estudios histopatológicos. Respecto a los diferentes modelos, hay infinidad de posibles variaciones según el modelo de trauma que se use, el intervalo de tiempo transcurrido entre los episodios y el número de traumas causados previamente al sacrificio del animal. Sin embargo, todavía no hay ningún modelo que se haya reconocido claramente superior en la literatura científica. Un estudio reciente de daño traumático por repetición del impacto en ratones ha mostrado que si el segundo trauma se produce a los tres o cinco días del trauma inicial, el daño es mayor que si se produce a los siete días ${ }^{70}$.

\section{Modelos in vitro}

Se trata de modelos muy simples que permiten estudiar de forma directa la respuesta celular frente a un daño mecánico en el sistema nervioso central. Estos modelos suponen la mejor herramienta para simplificar y estudiar las alteraciones celulares individuales. A diferencia de los modelos in vivo, se trata de modelos con un control biomecánico muy estricto en los que es posible testar más rápidamente la eficacia de potenciales agentes terapéuticos ${ }^{66}$. Sin embargo, su limitación más importante es la difícil correlación con el daño observado en pacientes porque los estudios in vitro se limitan a la observación en cultivos celulares y carecen de la complejidad de las alteraciones fisiopatológicas observadas en la clínica. A continuación expondremos de forma general los principales modelos de daño traumático in vitro.

\section{Modelo de arañado/rasgado}

Consiste en la lesión directa de células nerviosas con una aguja. Se desarrolló inicialmente sobre porciones de tejido nervioso ${ }^{33}$ y posteriormente en cultivos celulares ${ }^{111}$. Este modelo trata de reproducir la lesión del parénquima cerebral causado por la penetración de un proyectil o por una fractura deprimida.

\section{Compresión por caída de peso}

Es un modelo más avanzado que consiste en aplicar una compresión mecánica con un peso en cultivos celulares. Se puede aplicar también a los cultivos organotípicos, que tienen un grosor definido y una estructura tridimensional más realista (Figura 6-A).

Se ha demostrado recientemente con este modelo la generación de una onda de "spreading depresion" que puede desencadenarse tras el daño tisular mecánico e influir en las alteraciones funcionales del tejido a distancia del área de impacto ${ }^{23}$. Sin embargo, el daño por compresión directa del parénquima cerebral es raro en la práctica clínica y suele estar asociado a fracturas craneales.

\section{Modelo de estiramiento celular}

Es el modelo más frecuentemente usado en los estudios experimentales y por ello el que expondremos con más detalle. Trata de reproducir la deformación tisular que se produce durante la acción de fuerzas de inercia sobre el cráneo in vivo ${ }^{80}$. El modelo inicial consistía en el estiramiento bidireccional de dos membranas elásticas entre las que se disponían células en cultivo. Inicialmente este modelo se utilizó para la investigación del daño de cultivos de astrocitos pero rápidamente se aplicó a culti- 
vos de neuronas y a cultivos mixtos neurogliales ${ }^{19,83}$. Una variación posterior del modelo consistió en el estiramiento de las células en cultivo en una sola dirección ${ }^{87,71}$ (Figura 6-B). Con el estiramiento de las neuronas que tienen sus prolongaciones alineadas longitudinalmente y paralelas a la dirección de la tensión en cultivo, se trata de reproducir la lesión axonal difusa ${ }^{101}$.

\section{Modelos intermedios}

Uno de los últimos avances en el desarrollo de modelos experimentales de TCE, se basa en el diseño de modelos con una complejidad intermedia entre los modelos in vivo e in vitro, como el modelo tisular tridimensional. Estos nuevos modelos permiten aplicar el tipo de fuerza deseada de tal forma que se imiten de forma más aproximada las fuerzas que tienen lugar in vivo sobre un área de tejido. Consiste en cultivar las células en un hidrogel (cultivos mixtos neurogliales) de tal forma que la deformación de los cultivos resulta en campos de tensiones heterogéneas a nivel celular, dependiendo de la orientación de la célula en la matriz ${ }^{65}$.

\section{Conclusiones}

Debido a la importante repercusión que el TCE tiene en la sociedad, resulta fundamental mejorar la comprensión de las múltiples alteraciones fisiopatológicas implicadas en el desarrollo de las lesiones cerebrales postraumáticas para poder de este modo idear tratamientos específicos frente a las mismas. En la actualidad, el cuidado de los pacientes que han sufrido un TCE consiste en evacuar las lesiones con efecto de masa, si éstas están presentes, junto con medidas paliativas de soporte que ayuden a mantener el cerebro bien perfundido. Los modelos experimentales tratan de simplificar la condición del TCE en humanos con el objetivo de ser reproducibles y crear condiciones controlables. Suponen una herramienta fundamental para estudiar los mecanismos subyacentes al daño cerebral traumático como paso previo al desarrollo de terapias específicas. Los modelos experimentales deberían idealmente reproducir la fisiopatología del daño humano. Sin embargo, puesto que se trata de una patología muy heterogénea, que incluye diferentes tipos de daño difuso y/o focal, no puede haber un solo modelo experimental que reproduzca todos los aspectos del daño traumático humano.

Los modelos in vivo preservan en gran medida la complejidad del TCE en condiciones clínicas, al mismo tiempo que permiten manipular ciertos parámetros que no son controlables en la investigación clínica. Teniendo en cuenta todos los modelos existentes, no se puede recomendar ninguno como el ideal para la investigación en el campo de la neurotraumatología. Cada modelo animal ofrece unas ventajas, pero también limitaciones, que se deben considerar al diseñar un experimento. La elección del modelo debe tener en cuenta los objetivos específicos de cada estudio. Los modelos in vitro ofrecen algunas ventajas sobre los modelos animales, como el aislamiento de parámetros específicos y la evaluación de forma sistemática de las respuestas celulares frente a determinados estímulos. Los cultivos celulares pueden someterse a fuerzas de compresión o de estiramiento para mimificar los aspectos del trauma in vivo. Existe controversia sobre la necesidad de desarrollar nuevos modelos experimentales de TCE. Algunos investigadores consideran que no es necesario tratar de desarrollar nuevos modelos pues al tratarse de una patología muy heterogénea sólo es posible estudiar su fisiopatología evaluando cada aspecto por separado. Sin embargo, otros consideran que es necesario desarrollar un modelo más complejo y que reproduzca mejor la heterogeneidad del daño cerebral traumático observado en la práctica clínica.

\section{Bibliografía}

1. Adams, J.H., Graham, D.I., Genarelli, T.A.: Neuropathology of acceleration-induced head injury in the subhuman primate, in Grossman, R.G., Gildenberg, P.L.: Head Injury: Basic and Clinical Aspects, New York: Raven Press, 1982, pp 141-150.

2. Adams, J.H., Graham, D.I., Gennarelli, T.A.: Head injury in man and experimental animals. Acta Neurochir [Suppl] 1983; 32: 15-30.

3. Adams, J.H., Doyley, D., Ford, I., Gennarelli, T.A., Graham, D.I., McLellan, D.R.: Diffuse axonal injury in head injury: definition, diagnosis and grading. Histopathology 1989; 15: 49-59.

4. Adelson, P.D., Dixon, C.E., Robichaud, P., Kochanek, P.M.: Motor and cognitive functional deficits following diffuse traumatic brain injury in the immature rat. J Neurotrauma 1997; 14: 99-108.

5. American Academy of Neurology: The management of concussion in sports. Neurology 1997; 48: 581-585.

6. Anderson, R.W., Brown, C.J., Blumbergs, P.C., McLean, A.J., Jones, N.R.: Impact mechanics and axonal injury in a sheep model. J Neurotrauma 2003; 20: 961-974.

7. Barzo, P., Marmarou, A., Fatouros, P., Corwin, F., Dunbar, J.: Magnetic resonance imaging-monitored acute blood-brain barrier changes in experimental traumatic brain injury. J Neurosurg 1996; 85: 1113-1121.

8. Barzo, P., Marmarou, A., Fatouros, P., Hayasaki, K., Corwin, F.: Contribution of vasogenic and cellular edema to traumatic brain swelling measured by diffusion-weighted imaging. J Neurosurg 1997; 87: 900-907.

9. Baskaya, M.K., Rao, A.M., Dogan, A., Donalson, D., 
Dempsey, R.J.: The biphasic opening of the blood-brain barrier in the cortex and hippocampus after traumatic brain injury in rats. Neurosci Lett 1997; 226: 33-36.

10. Beaumont, A., Marmarou, A., Fatouros, P., Corwin, F.: Secondary insults worsen blood brain barrier dysfunction assessed by MRI in cerebral contusion. Acta Neurochir [Suppl] 2002; 81: 217-219.

11. Bouma, G.J., Muizelaar, J.P., Choi, S.C., et al.: Cerebral circulation and metabolism after severe traumatic brain injury: the elusive role of ischemia. J Neurosurg 1991; 75: 685-695.

12. Bramlett, H.M., Kraydieh, S., Green, E.J., Dietrich, W.D.: Temporal and regional patterns of axonal damage following traumatic brain injury: a betaamyloid precursor protein immunocytochemical study in rats. J Neuropathol Exp Neurol 1997; 56, 1132-1141.

13. Bramlett, H.M., Dietrich, W.D., Green, E.J.: Secondary hypoxia following moderate fluid percussion brain injury in rats exacerbates sensorimotor and cognitive deficits. J Neurotrauma 1999; 16: 1035-1047.

14. Bruns, J. Jr., Hauser, W.A.: The epidemiology of traumatic braininjury: a review. Epilepsia 2003; 44: 2-10.

15. Bullock, M.R., Chesnut, R., Ghajar, J., et al.: Surgical management of TBI author group. Introduction. Neurosurgery 2006; 58: S2-1-S2-3.

16. Cantu, R.C., Mueller, F.O.: Brain injury-related fatalities in American football, 1945-1999. Neurosurgery 2003; 52 : 846-852.

17. Carbonell, W.S., Maris, D.O., McCall, T., Grady, M.S.: Adaptation of the fluid percussion injury model to the mouse. J Neurotrauma 1998; 15: 217-229.

18. Carbonell, W.S., Grady, M.S.: Regional and temporal characterization of neuronal, glial and axonal response after traumatic brain injury in the mouse. Acta Neuropathol (Berl) 1999; 98: 396-406.

19. Cargill, R.S. $2^{\text {nd }}$, Thibault, L.E.: Acute alterations in $\left[\mathrm{Ca}^{2+}\right] \mathrm{i}$ in NG108-15 cells subjected to high strain rate deformation and chemical hypoxia: an in vitro model for neural trauma. J Neurotrauma 1996; 13: 395-407.

20. Cernak, I., Vink, R., Zappie, D.N., et al.: The pathobiology of moderate diffuse traumatic brain injury as identified using a new experimental model of injury in rats. Neurobiol Dis 2004; 17: 29-43.

21. Cernak, I.: Animal Models of Head Injury. NeuroRx: The Journal of the American Society for Experimental NeuroTherapeutics 2005; 2: 410-422.

22. Chesnut, R.M., Marshall, L.F., Klauber, M.R., et al.: The role of secondary brain injury in determining outcome from severe head injury. J Trauma 1993; 34: 216-22.

23. Church, A.J., Andrew, R.D.: Spreading depression expands traumatic injury in neocortical brain slices. J Neurotrauma 2005; 22: 277-290.

24. Clark, R.S., Kochanek, P.M., Dixon, C.E., Chen, M., et al.: Early neuropathologic effects of mild or moderate hypoxemia after controlled cortical impact injury in rats. $\mathrm{J}$ Neurotrauma 1997; 14: 179 -189.

25. Clubb, R.J., Maxwell, R.E., Chou, S.: Experimental brain injury in the dog. The pharmacological effects of pentobarbital and sodium nitropusside. J Neurosurg 1980; 52: 189-196.

26. Coats, B., Margulies, S.S.: Material properties of porcine parietal cortex. J Biomech 2006; 39: 2521-2525.

27. Conti, A.C., Raghupathi, R., Trojanowski, J.Q., McIntosh, T.K.: Experimental brain injury induces regionally distinct apoptosis during the acute and delayed post-traumatic period. J Neurosci 1998; 18: 5663-5672.

28. Cortez, S.C., McIntosh, T.K., Noble, L.J.: Experimental fluid percussion brain injury: vascular disruption and neuronal and glial alterations. Brain Res 1989; 482, 271282.

29. Denny-Brown, D.: Cerebral concussion. Physiol Rev 1945; 25: 296-325. Langlois, J.A., Ruthlan-Brown, W., Wald, M.M.: The epidemiology and impact of traumatic brain injury: a brief overview. J Head Trauma Rehabil 2006; 21: 375-378.

30. Dixon, C.E., Lyeth, B.G., Povlishock, J.T., et al.: A fluid percussion model of experimental brain injury in the rat. J Neurosurg; 1987; 67: 110-119.

31. Dixon, C.E., Lighthall, J.W., Anderson, T.E.: Physiologic, histopathologic, and cineradiographic characterization of a new fluid-percussion model of experimental brain injury in the rat. J Neurotrauma 1988; 5: 91-104.

32. Dixon, C.E., Clifton, G.L., Lighthall, J.W., Yaghmai, A.A., Hayes, R.L.: A controlled cortical impact model of traumatic brain injury in the rat. J Neurosci Methods 1991; 39: 253-262.

33. Epstein, M.H.: Relative susceptibility of elements of the cerebral cortex to mechanical trauma in the rat. J. Neurosurg 1971; 35: 517-522.

34. Eriskat, J., Fürst, M., Stoffel, M., Baethmann, A.: Correlation of lesion volume and brain swelling from a focal brain trauma. Acta Neurochir (Wien) [Suppl] 2003; 86: 265266.

35. Faden, A.I.: Neuroprotection and traumatic brain injury: theoretical option or realistic proposition. Curr Opin Neurol 2002; 15: 707- 712.

36. Feeney, D.M., Boyeson, M.G., Linn, R.T., Murray, H.M., Dail, W.G.: Responses to cortical injury. I. Methodology and local effects of contusions in the rat. Brain Res 1981; 211: 67-77.

37. Fleminger, S., Ponsford, J.: Long term outcome after traumatic brain injury. BMJ 2005; 331: 1419-1420.

38. Foda, M.A., Marmarou, A.: A new model of diffuse brain injury in rats: Part II. Morphological characterization. J Neurosurg 1994; 80: 301-313.

39. Gennarelli, T.A.: Head injury in man and experimental 
animals: clinical aspects. Acta Neurochir [Suppl] 1983; 32: 113.

40. Gennarelli, T.A., Thibault, L.E, Adams, J.H., Graham, D.I., Thompson, C.J., Marcincin, R.P.: Diffuse axonal injury and traumatic coma in the primate. Ann Neurol 1982; 12: 564574.

41. Gennarelli, T.A.: Mechanisms of brain injury. J Emerg Med 1993; 11: 5-11.

42. Gennarelli, T.A.: Animate models of human head injury. J Neurotrauma 1994; 11: 357-368.

43. Goodman, J.C., Cherian, L., Bryan, R.M. Jr, Robertson, C.S.: Lateral cortical impact injury in rats: Pathologic effects of varying cortical compression and impact velocity. $\mathrm{J}$ Neurotrauma 1994; 11: 587-597.

44. Graham, D.I., Raghupathi, R., Saatman, K.E., Meaney, D., McIntosh, T.K.: Tissue tears in the white matter after lateral fluid percussion brain injury in the rat: relevance to human brain injury. Acta Neuropathol Berl; 2000: 99, 117 124.

45. Graham, D.I., Gennarelli, T.A., McIntosh, T.K.: Cellular and molecular consequences of TBI. En Graham, D.I., Luntus, P.L., (eds). Greenfield's neuropathology 2002; pp. 823-898.

46. Guskiewicz, K.M., McCrea, M., Marshall, S.W., et al: Cumulative effects associated with recurrent concussion in collegiate football players: the NCAA Concussion Study. JAMA 2003; 290: 2549-2555.

47. Gutierrez, E., Huang, Y., Haglid, K., et al.: A new model for diffuse brain injury by rotacional acceleration: I. model, gross appearance and astrocytosis. J Neurotrauma 2001; 18: 247-257.

48. Hall, E.D., Sullivan, P.G., Gibson, T.R., Pavel, K.M., Thompson, B.M., Scheff, S.W.: Spatial and temporal characteristics of neurodegeneration after controlled cortical impact in mice: More than a focal brain injury. J Neurotrauma 2005; 22: 252-265.

49. Hayes, R.L., Stalhammar, D., Povlishock, J.T., et al.: A new model of concussive brain injury in the cat produced by extradural fluid volume loading. II. Physiological and neuropathological observations. Brain Inj 1987; 1: 93112.

50. Hicks, R., Soares, H., Smith, D., McIntosh, T.: Temporal and spatial characterization of neuronal injury following lateral fluid-percussion brain injury in the rat. Acta Neuropathol (Berl) 1996; 91: 236-246.

51. Holbourn, A.H.: Mechanics of head injuries. Lancet 1943; $2:$ 438-441.

52. Hurley, R.A., McGowan, J.C., Arfanakis, K., Taber, K.H.: Traumatic axonal injury: novel insights into evolution and identification. J Neuropsychiatry Clin Neurosci 2004; 16 : 1-7.

53. Ishige, N., Pitts, L., Berry, J., Carlson, S., Nishimura, M., Moseley, M., Weinstein, P.: The effects of hypoxia on trau- matic head injury in rats: alterations in neurologic function, brain edema, and cerebral blood flow. J Cereb Blood Flow Metab 1987; 7: 750-767.

54. Jakobsson, K.E., Thuomas, K.A., Berstrom, K., Ponten, U., Zwetnow, N.N.: Rebound of ICP after brain compression. An MRI study in dogs. Acta Neurochir 1990; 104: 126-135.

55. James, H.E., Schneider, S.: Cryogenic brain oedema: loss of cerebrovascular autoregulation as a cause of intracranial hypertension. Implications for treatment. Acta Neurochir (Wien) [Suppl] 1990; 51: 79-81.

56. Jordan, B.D.: Chronic traumatic brain injury associated with boxing. Semin. Neurol 2000; 20: 179-185.

57. Kimelberg, H.K.: Current concepts of brain edema: review of laboratory investigations. J Neurosurg 1995; 83: 1051-1059.

58. Kita, H., Marmarou, A.: The cause of acute brain swelling after the closed head injury in rats. Acta Neurochir Suppl [Wien] 1994; 60: 452-455.

59. Klatzo, I., Piraux, A., Laskowski, E.J.: The relationship between edema, blood brain barrier and tissue elements in a local brain injury. J Neuropathol Exp Neurol 1958; 17: 548564.

60. Kochanek, P.M., Marion, D.W., Zhang, W., et al.: Severe controlled cortical impact in rats: assessment of cerebral edema, blood flow and contusion volume. J Neurotrauma 1995; 12: 1015-1025.

61. Kotapka, M.J., Graham, D.I., Adams, J.H., Gennare1li, T.A.: Hippocampal pathology in fatal human head injury without high intracranial pressure. J Neurotrauma 1994; 11 : 317-324.

62. Lammie, G.A., Piper, I.R., Thomson, D., Brannan, F.: Neuropathologic characterization of a rodent model of closed head injury-addition of clinically relevant secondary insults does not significantly potentiate brain damage. J Neurotrauma 1999; 16: 603-615.

63. Langfitt, T.W., Tannabaum, H.M., Kassell, N.F.: The etiology of acute brain swelling following experimental head injury. J Neurosurg 1966; 24: 47-56.

64. Langlois, J.A., Rutland-Brown, W., and Tomas, K.E.: Traumatic brain injury in the United States: emergency department visits, hospitalization, and deaths. Atlanta, GA: Centers for Disease Control and Prevention, National Center of Injury Prevention and Control. 2004.

65. LaPlaca, M.C., Cullen, D.K., McLoughlin, J.J., Cargill, R.S $2^{\text {nd }} .:$ High rate shear strain of three-dimensional neural cell cultures: a new in vitro traumatic brain injury model. J Biomech 2005; 38: 1093-1105.

66. La Placa, M.C., Simon, C.M., Prado, G.R., Cullen, D.K.: CNS injury biomechanics and experimental models. Prog Brain Res 2007; 161: 13-26.

67. Leker, R.R., Shohami, E., Constantini, S.: Experimental models of Head Trauma. Acta Neurochir [Suppl] 2002; 83: 
49-54.

68. Lighthall, J.W.: Controlled cortical impact: a new experimental brain injury model. J Neurotrauma 1988; 5: $1-5$.

69. Lindenberg, R. Pathology of craniocerebral injuries. En Newton, T.H., Patts, D.G., (eds). Radiology of the skull and brain: anatomy and physiology 1977; pp. 3049-3087.

70. Longhi, L., Saatman, K.E., Fujimoto, S., et al.: Temporal window of vulnerability to repetitive experimental concussive brain injury. Neurosurgery 2005; 56: 364-374.

71. Lusardi, T.A., Rangan, J., Sun, D., Smith, D.H., Meaney, D.F.: A device to study the initiation and propagation of calcium transients in cultured neurons after mechanical stretch. Ann Biomed Eng 2004; 32: 15461558.

72. Margulies, S.S., Thibault, L.E., Gennarelli T,A.: Physical model simulations of brain injury in the primate. J Biomech 1990; 23: 823-836.

73. Marmarou, A., Foda, M., Van den Brink, W., Campbell, J., Kita, H., Demetriadou K.: A new model of diffuse brain injury in rats: Part I. Pathophysiology and biomechanis. J Neurosurg 1994; 80: 291-300.

74. Marmarou, A., Hochwald, G., Nakamura, T., Tanaka, K., Weaver, J., Dunbar, J.: Brain edema resolution by CSF pathways and brain vasculature in cats. Am J Physiol 1994; 267: H415-520.

75. Marmarou, A.: Pathophysiology of traumatic brain edema: current concepts. Acta Neurochir Suppl 2003; 86: 710 .

76. Marshall, W.J., Jackson, J.L., Langfitt, T.W.: Brain swelling caused by trauma and arterial hypertension: hemodynamic aspects. Arch Neurol 1969; 21: 545-553.

77. Maxwell, W.L., Povlishock, J.T., Graham, D.I.: A mechanistic analysis of nondisruptive axonal injury: a review. J Neurotrauma 1997; 14: 419-440.

78. McIntosh, T.K., Noble, L., Andrews, B., Faden, A.I.: Traumatic brain injury in the rat: characterization of a midline fluid-percussion model. Cent Nerv Syst Trauma 1987; 4: 119134.

79. McIntosh, T.K., Vink, R., Noble, L., et al.,: Traumatic brain injury in the rat: characterization of a lateral fluid-percussion model. Neuroscience 1989; 28: 233-244.

80. Meaney, D.F., Smith, D.H., Shreiber, D.I., et al.: Biomechanical analysis of experimental diffuse axonal injury. $\mathrm{J}$ Neurotrauma 1995; 12: 689-694.

81. Miller, J.D., Stanek, A.E., Langfitt, T.W.: Cerebral blood flow regulation during experimental brain compression. J Neurosurg 1973; 39: 186-196.

82. Morales, D.M., Marklund, N., Lebold, D., et al.: Experimental models of traumatic brain injury: do we really need to build a better mousetrap? Neuroscience 2005; 136 :
971-989.

83. Morrison, B. $3^{\text {rd, }}$ Meaney, D.F., McIntosh, T.K.: Mechanical characterization of an in vitro device designed to quantitatively injure living brain tissue. Ann Biomed Eng 1998; 26: 381-390.

84. Nilsson, B., Nordström, C.H.: Experimental head injury in the rat. Part 3: Cerebral blood flow and oxygen consumption after concussive impact acceleration. J Neurosurg 1977; 47: 262-273.

85. Ommaya, A.K., Yarnell, P., Hirsch, A.E., Harris, E.H.: Scaling of experimental data on cerebral concussion in subhuman primates to concussion threshold for man. In $13^{\text {th }}$ Stapp Car Crash Conference, Anaheim, C.A, Society of Automovies Engineers. 1967.

86. Pascual, J.M., Solivera, J., Prieto, R., et al.: Time course of early metabolic changes following diffuse traumatic brain injury in rats as detected by $1(\mathrm{H})$ NMR spectroscopy. J Neurotrauma 2007; 24: 944-959.

87. Pfister, B.J., Weihs, T.P., Betenbaugh, M., Bao, G.: An in vitro uniaxial stretch model for axonal injury. Ann Biomed Eng 2003; 31: 589-598.

88. Povlishock, J.T., Hayes, R.L., Michel, M.E., McIntosh, T.K.: Workshop on animal models of traumatic brain injury. J Neurotrauma 1994; 11: 723-732.

89. Povlishock, J.T., Buki, A., Koizume, H., Stone, J., Okonkwo, D.O.: Initiating mechanisms involved in the pathobiology of traumatically induced axonal injury and interventions targeted at blunting their progression. Acta Nerochir [Suppl] 1999; 73: 15-20.

90. Povlishock, J.T.: Pathophysiology of neural injury: therapeutic opportunities and challenges. Clin Neurosurg 2000; 46:113-126.

91. Povlishock, J.T., Katz, D.I.: Update of neuropathology and neurological recovery after traumatic brain injury. J Head Trauma Rehabil 2005; 20: 76-94.

92. Prange, M.T., Margulies, S.S.: Regional, directional, and age-dependent properties of the brain undergoing large deformation. J Biomech Eng 2002; 124: 244-252.

93. Prieto, R., Tavazzi, B., Taya, K., Barrios, L., Marmarou, C.R., Marmarou A.: Brain energy depletion caused by a diffuse head injury in rats is not ameliorated by the infusion of sodium lactate. J Neurotrauma 2008; 25: 868.

94. Reulen, H.J., Tsuyumu, M., Tack, A., Fenske, A.R., Prioleau, G.R.: Clearance of edema fluid into cerebrospinal fluid. A mechanism for resolution of vasogenic edema. J Neurosurg 1978; 48: 754-764.

95. Ross, D.T., Meaney, D.F., Sabol, M., Smith, D.H., Thibault, L.E., Gennarelli, T.A.: Distribution of forebrain diffuse axonal injury following inertial closed head injury in miniature swine. Exp Neurol 1994; 26: 291-299.

96. Sahuquillo, J. and Poca, M.A.: Diffuse Axonal Injury after Head Trauma. A review. Adv Tech Stand Neurosurg 2002; 27: 23-86. 
97. Shapira, Y., Shohami, E., Sidi, A., Soffer, D., Freeman, S., Cotev, S.: Experimental closed head injury in rats: mechanical, pathophysiologic and neurologic properties. Crit Care Med 1988; 16: 258-265.

98. Smith, D.H., Soares, H.D., Pierce, J.E.S., et al.: A model of parasagittal controlled cortical impact in the mouse: cognitive and histopathologic effects. J Neurotrauma 1995; 12: $169-178$.

99. Smith, D.H., Chen, X.H., Piercem J.E., et al.: Progressive atrophy and neuron death for one year following brain trauma in the rat. J Neurotrauma 1997; 14: 715727.

100. Smith, D.H., Chen, X.H., Xu, B.N., McIntosh, T.K., Gennarelli, T.A., Meaney, D.F.: Characterization of diffuse axonal pathology and selective hippocampal damage following inertial brain trauma in the pig. J Neuropathol Exp Neurol. 1997; 56: 822-834.

101. Smith, D.H., Wolf, J.A., Lusardi, T.A., Lee, V.M., Meaney, D.F.: High tolerance and delayed elastic response of cultured axons to dynamic stretch injury. J Neurosci 1999; 19: 4263-4269.

102. Stalhammar, D., Olsson, Y.: Experimental brain damage from fluid pressures due to impact acceleration. Acta Neurol Scand 1975; 52: 38-55.

103. Stalhammar, D., Galinat, B.J., Allen, A.M., Becker, D.P., Stonnington, H.H., Hayes R.L.: A new model of concussive brain injury in the cat produced by extradural fluid volume loading: I. Biomechanical properties. Brain Inj 1987; 1: 73-91.

104. Statler, K.D., Jenkins, L.W., Dixon, C.E., Clark, R.S., Marion, D.W., Kochanek, P.M.: The simple model versus the super model: translating experimental traumatic brain injury research to the bedside. J Neurotrauma 2001; 18 : 1195-206.

105. Stone, J.R., Singleton, R.H., Povlishock, J.T.: Antibodies to the Cterminus of the beta-amyloid precursor protein (APP): a site specific marker for the detection of traumatic axonal injury. Brain Res 2000; 871: 288-302.

106. Stone, J.R., Okonkwo, D.O., Dialo, A.O., Rubin, D.G., Mutlu, L.K., Povlishock, J.T., Helm, G.A.: Impaired axonal transport and altered axolemmal permeability occur in distinct populations of damaged axons following traumatic brain injury. Exp Neurol 2004; 190: 59-69.

107. Stroop, R., Thomale, U., Pauser, S., et al.: Magnetic resonance imaging studies with cluster algorithm for characterization of brain edema after controlled cortical impact injury (CCII). Acta Neurochir Suppl 1998; 71: 303305.

108. Sullivan, H.G., Martinez, J., Becker, D.P., Miller, J.D., Griffith, R., Wist, A.O.: Fluid-percussion model of mechanical brain injury in the cat. J Neurosurg 1976; 45: 521-534.

109. Tagliaferri, F., Compagnonge, C., Korsic, M.,
Servadei, F., Kraus, J.: A systematic review of brain injury epidemiology in Europe. Acta Neurochir (Wien) 2006; 148: 255-268.

110. Tang, Y.P., Noda, Y., Hasegawa, T., Nabeshima, T.: A concussivelike brain injury model in mice (II): selective neuronal loss in the cortex and hippocampus. J Neurotrauma 1997; 14: 863-873.

111. Teasdale, G.M., Maas, A., Iannotti, F., Ohman, J., Unterberg, A.: Challenges in translating the efficacy of neuroprotective agents in experimental models into knowledge of clinical benefits in head injured patients. Acta Neurochir Suppl 1999; 73: 111-116.

112. Tecoma, E.S., Monyer, H., Goldberg, M.P, Choi, D.W.: Traumatic neuronal injury in vitro is attenuated by NMDA antagonists, Neuron 1989; 2: 1541-1545.

113. Thibault, L.E., Meaney, D.F., Anderson, B.J., Marmarou, A.: Biomechanical aspects of a fluid percussion model of brain injuiry. J Neurotrauma 1992; 9: 311-322.

114. Thompson, H.J., Lifshitz, J., Marklund, N., et al.: Lateral Fluid Percussion Brain Injury: A 15-Year Review and Evaluation. J Neurotrauma 2005; 22: 42-75

115. Thurman, D.J., Alverson, C., Dunn, K.A., Guerrero, J., Sniezek, J.E.: Traumatic brain injury in the United States: a public health perspective. J Head Trauma Rehabil 1999; 14: 602-615.

116. Tood, M.M., Weeks, J.B, Warner, D.S.: A focal cryogenic brain lesion does nor reduce the minimum alveolar concentration for halothane in rats. Anesthesiology 1993; 79: 139-143.

117. Unterberg, A.W., Stover, J., Kress, B., Kiening, K.L.: Edema and brain trauma. Neuroscience 2004; 129: 10211029.

118. Vink, R., Mullins, P.G., Temple, M.D., Bao, W., Faden, A.I.: Small shifts in craniotomy position in the lateral fluid percussion injury model are associated with differential lesion development. J. Neurotrauma 2001; 18: 839-847.

119. Vink, R., Nimmo, A.J.: Novel therapies in development for the treatment of traumatic brain injury. Expert Opin Investig Drugs 2002; 11: 1375-1386.

120. Wall, S.E., Williams, W.H., Cartwright-Hatton, S., et al.: Neuropsychological dysfunction following repeat concussions in jockeys. J Neurol Neurosurg Psychiatry 2006; 77 : 518-520.

121. Weber, J.T.: Experimental models of repetitive brain injuries. Prog Brain Res 2007; 161: 253-261.

122. Yamaguchi, M., Shirakata, S., Yamasaki, S.: Ischemic brain edema and compression brain edema. Water content, blood-brain barrier and ciruclation. Stroke 1976; 7: 77-83.

123. Yamamoto, M., Marmarou, C,R., Stiefel, M.F., Beaumont, A., Marmarou, A.: Neuroprotective effect of hypothermia on neuronal injury in diffuse traumatic brain injury 
coupled with hypoxia and hypotension. J Neurotrauma 1999; 16: 487-500.

124. Yuan, X.Q., Prough, D.S., Smith, T.L., DeWitt, D.S.: The effects of traumatic brain injury on regional cerebral blood flow in rats. J Neurotrauma 1988; 5: 289-301.

125. Zhang, L., Yang K.H., King, A.I.: A proposed injury threshold for mils traumatic brain injury. J Biomech Eng 2004; 126: 226-236.
Prieto, R.; Gutiérrez-González, R.; Pascual, J.M.; Roda, J.M.; Cerdán, S.; Matias-Guiu, J.; Barcia, J.A.: Modelos experimentales de traumatismo craneoencefálico. Neurocirugía 2009; 20: 225-244.

Correspondencia postal: Ruth Prieto. Servicio de Neurocirugía, Hospital Universitario Clínico San Carlos. Planta Sexta -Ala Sur. Profesor Martin Lagos s/n, 28040 Madrid. 